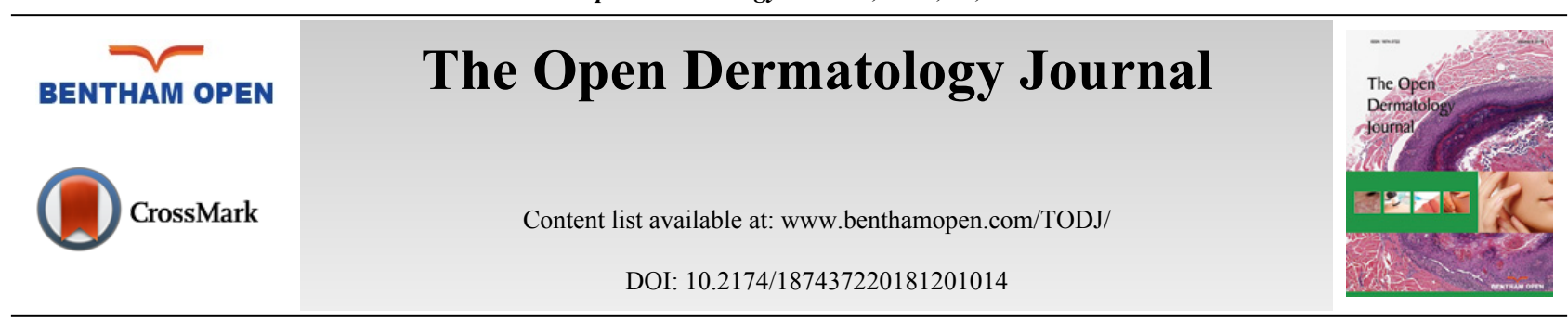

REVIEW ARTICLE

\title{
A Review of Prevalent Methods for Automatic Skin Lesion Diagnosis
}

\author{
Damilola A Okuboyejo ${ }^{*}$ and Oludayo O Olugbara \\ ICT and Society Research Group, Durban University of Technology, Durban, South Africa
}

Received: November 14, 2017

Revised: December 06, 2017

Accepted: March 27, 2018

\begin{abstract}
:
Background:

Skin cancer has been reported to be one of the most predominant forms of cancer diseases, especially amongst Caucasian descendant and light-skinned people. In particular, the melanocytic skin lesion has been judged to be the most deadly amongst three prevalent skin cancer diseases and the second most common form amongst young adults ranging from 15-29 years of age. These concerns have propelled the need to provide automated systems for medical diagnosis of skin cancer diseases within a strict time window towards reducing the unnecessary biopsy, increasing the speed of diagnosis and providing reproducibility of diagnostic results.
\end{abstract}

\section{Objective:}

This paper is aimed at using a comparative analysis method to review and compare the existing novel approaches for automating the diagnostic procedures of melanocytic skin lesion, including their success and shortcomings. This task is particularly valuable for decision makers to consider tradeoffs inaccuracy of diagnostic procedure versus complexity.

\section{Methods:}

A comparative study was carried out on selected literature from different accessible digital libraries of skin lesion research, especially cancerous moles in regard to the convention used, assumptions made, success recorded and noticeable gaps that need to be adequately filled by further study.

\section{Conclusion:}

Image standardization should be embraced in the medical research community to ensure the reproducibility of findings. Moreover, efforts should be made to have a large image library of varying skin lesion samples with categories based on lesion types and making these accessible to researchers to ensure proper benchmarking of research results.

Keywords: Computer-assisted dermoscopy, Skin lesion segmentation, Pattern recognition, Remote health diagnosis, Medical image analysis, Computational intelligence, Melanoma skin disease, Automated diagnosis.

\section{INTRODUCTION}

Skin cancer has been reported to be one of the most predominant forms of cancer disease, especially amongst the Caucasian descendant and light-skinned people. In particular, the melanoma has been judged to be the most deadly form of skin cancer among the three prevalent skin cancer diseases and equally adjudicated as the fifth most common cancer occurring among males, seventh most commonly occurring form of cancer diseases in females and second most common form of cancer diseases amongst young adults ranging from 15-29 years of age. These concerns have compelled the need to provide medical diagnosis within a very strict time frame through the application of advances in telecommunications-based services. Moreover, this application has been geared towards reducing unnecessary biopsy, increasing the speed of diagnosis and providing reproducibility of diagnostic results.

\footnotetext{
* Address correspondence to this author at the ICT and Society Research Group, Durban University of Technology, P.O. Box 1334, 4000, Durban, South Africa; E-mail: d.okuboyejo@gmail.com
} 
This study reviews the state-of-the-art approaches for achieving an automated skin lesion image diagnosis. Section 2 provides an overview of the anatomy of the skin in relation to the focus of the paper. The analysis of medical imaging in fostering a good decision-making process for skin diagnosis is discussed in Section 3. The computer-aided diagnostic system for the development of automated skin lesion diagnosis process is illustrated in Section 4. Current and state-ofthe-art skin lesion diagnostic methods for assisting the diagnosis of melanocytic lesions are reviewed in Section 5. Homogenous skin lesion diagnostic procedures frequently used in the research community are comprehensively discussed in Section 6. We conclude our findings with the proposed recommendation in Section 7.

\section{HUMAN SKIN}

The surface of human skin is a detailed landscape with complex geometry and local optical properties. The skin is the largest organ of the human body and consists of three principal layers which are the epidermis (see 2.1 Epidermis), the dermis (see 2.2 Dermis) and the subcutaneous layer (see 2.3 Subcutaneous). Skin features depend heavily on many essential variables such as body location (forehead or cheek), subject parameters (age or gender), imaging parameters (lighting or camera) and the direction from which it is viewed and illuminated. Bacterial and viral skin infections generally affect the human skin by decolourizing and distorting the pigmented skin areas which make the automation of medical image analysis difficult [1].

\subsection{Epidermis}

The epidermis is a layered scale-like tissue which serves as a protection against external belligerences (extreme radiation, wounds and contaminations). The epidermis consists of four types of cells, which are Keratinocytes, Melanocytes, Langerhans and Merkel cells.

\subsection{Dermis}

The dermis is composed of collagen and elastic fibres. The dermis has two primary sub-layers which are the Papillary dermis (thin layer) that acts as a glue to hold the epidermis, and the dermis and Reticular dermis (thick layer) that supplies energy and nutrition to the epidermis. It contains nerve endings, sweat glands, hair follicles, blood vessels and lymph vessels. In addition, it is responsible for healing and sense of touch.

\subsection{Subcutaneous}

The subcutaneous layer is responsible for supplying nutrients to the other two layers. The subcutis, being made of made of fat and connective tissue that helps to cushion and insulate the body.

\section{MEDICAL IMAGING OF THE SKIN}

The principal aim of image analysis is to use image processing techniques to provide a machine interpretation of an image, typically in a format that could foster effective decision-making process. Interestingly, while the merit of medical imaging is getting popular, the World Health Organization (WHO) reported in one of its findings that three quarters of the entire world population is yet to have access to medical imaging, which is an essential technique in the new age of telemedicine such as in automation of skin disease diagnosis [2]. Hitherto, medical imaging has contributed immensely towards advancing medical procedures. However, one notable challenge is that interpretation and analysis of medical imaging results are still heavily dependent on medical experts whose availability is low or non-existent for developing and underserved regions (especially rural settings).

The fundamental task of medical imaging of the human skin is the segmentation of a mole that provides essential output for the mole feature extraction and mole classification. A mole is a skin lesion that essentially results from the local proliferation of pigment cells (melanocytes). Due to its root in melanocytes, it can sometimes be referred to as melanocytic nevus (naevus). Typically, a mole can be congenital or acquired. Congenital melanocytic nevi are present at birth and sometimes referred to as a birthmark in some regions. Congenital moles are often classified based on size. Three main types of congenital moles include small-size nevi, medium-sized nevi and giant-sized (garment) nevi. Acquired melanocytic nevi generally appears at a later stage in childhood or adult life because of several reasons such as unprotected exposure to sun radiation, immune status, genetic factors and at times from unpredictable adverse event from medication [3]. Mole transformation from nevi into cutaneous melanoma has been reported in the literature to increase with age, especially the dysplastic nevi [4, 5]. A benign mole might grow to be cutaneous for 1 in every 200000 male and female under the age of 40, as well as for 1 in 33000 for males older than 20 years of age [4]. While 
most moles occurring in adolescents might not transform into cutaneous melanoma [4], it has been reported that precautions need to be taken for scheduled examination on suspicious moles because some malignant melanoma might masquerade clinically as benign lesions $[6,7]$.

A skin lesion could also be categorised as pigmented or non-pigmented, based on its colour resulting from melanin, blood or exogenous pigment. While most Pigmented Skin Lesions (PSL) are melanocytic (benign moles or malignant), some have been reported to be non-melanocytic [8,9]. Most moles could be said to be benign (not harmful). A cancerous mole, however, is malignant (life-threatening). Some reports have argued that a number of malignant melanomas stem from the preexisting benign nevi $[4,10]$.

Pathologically, melanocytic nevi are often classified based on the location reference of the nevi cells in the skin. Dermal or intradermal nevi are associated with nevus cells located in the dermis. Junctional nevus refers to a flat mole affiliated with nevus cells located at the junction of the epidermis and dermis. Compound nevi have nevus cells at the epidermal-dermal junction and equally within the dermis. The usage of dermoscope in the process of dermatoscopy has introduced the classification based on pigment patterns. A starburst nevus reflects radial lines around the periphery of a skin lesion. Blue nevi refer to uniform but structure less skin lesions that are steel blue in colour. Other common nevi include spitz, reticular, globular, eclipse, dysplastic (atypical), fried egg, lentiginous and cockade nevus.

Early detection of malignant moles is one of the essential keys to prevent untimely death resulting from skin cancer diseases [11 - 28]. The three prevalent skin cancers, according to the literature are Basal Cell Carcinoma (BCC), Squamous Cell Carcinoma (SCC) and Melanoma. The incidence of skin cancer diseases such as BCC, SCC and Melanoma has also been seen to increase rapidly throughout the world and it is gradually becoming one of the predominant forms of cancer diseases, especially in Caucasian population countries and among fair-skinned people [29 - 31]. Skin cancer incidence is on the order of 10 to 12 in Europe, 18 to 20 in the United States, and 30 to 40 in Australia per 100000 subjects [32]. The Australian Institute of Health and Welfare (AIHW) and Australian Association of Cancer Registries (AACR) detailed that more people have had skin cancer disease than all other cancer diseases combined in the past three decades [33]. Robinson [34], reported that 1 in 5 Americans develops skin cancer in the course of a lifetime. It has been reported that approximately $40 \%-50 \%$ of Americans who live up to the age of 65 have a high risk of having either BCC or SCC at least once [35].

Melanoma is a skin cancer typically resulting from an unpredictable disorder in the melanocytic cells, thus causing improper synthesis of the melanin. While melanoma might account for the least amongst the three aforementioned skin cancer types, it has, however, been umpired to account for $75-79 \%$ of skin cancer related deaths $[29,36]$. The literature records that Melanoma is the fifth most common cancer occurring amongst males, seventh most commonly occurring cancer in females, and second most common form of cancer amongst young adults ranging from 15-29 years of age [37, 38]. Melanoma, which is currently the third prevalent cancer in Australia, was reported to occur in 61.7 for every 100000 Australian men and 40.0 for every 100000 women [33]. In the same study, melanoma of the skin was judged to have accounted for 22800 Disability-Adjusted Life Years (DALYs) in Australia. DALYs depict years of healthy life lost either because of premature death or through living with illness or injury-bound disability. The study made by American Cancer Society (ACS) [36] has revealed that at least 1 person would likely die every hour as a result of melanoma. Similarly, the study [33] reported that melanoma of the skin accounts for 22800 DALYs in Australia. DALYs refer to years of healthy life that have otherwise been lost either as a result of illness or premature death. It has been projected that melanoma would have caused 10130 deaths in the year 2016 [36] and 9730 deaths are predicted for 2017 [39].

The incidence of cutaneous melanoma in Caucasian patients has been reported to increase historically in most parts of the world over the decades [40 - 42]. In Europe for instance, it has been reported that malignant melanoma incidence is steadily increasing by 5\% year-on-year, and it is responsible for $91 \%$ of skin cancer deaths [31]. Amazingly, most incidents are reported in the literature among Caucasians, but some reports state that black Africans and Asians account for $20 \%$ of the world melanoma [43, 44]. Tuma et al. [45], however, argued that the African descendant population is rarely affected by melanoma because an average of 1.1 out of 100,000 persons per year has an incidence of melanoma. Though most reports of melanoma have majorly reflected an infection rate among Caucasians, the overall five-year melanoma survival rate for African-Americans and other people of colour is only $77 \%$ compared to $91 \%$ for Caucasians [46]. A fact sheet report compiled by Cancer Association of South Africa (CASA) [47] has stated that South Africa has the second highest incidence of skin cancer in the world after Australia.

Gruesome reports as highlighted above have led to many advances in computer-aided systems towards assisting 
dermatologists to administer the diagnosis of skin-related diseases. The development of automated diagnosis systems that are capable of performing some level of remote diagnosis of skin cancer diseases such as melanoma and basal cell carcinoma and equally assisting physicians in various imaging tasks have gained tremendous attention in the bioinformatics and computer vision research [48].

The efforts towards the automation of diagnostic procedures are geared mainly to improve the speed of diagnosis and to increase reproducibility of results. The automated diagnosis has helped in reducing the first-time diagnostic errors, which sometimes could be as much as $40 \%[49,50]$.

\section{COMPUTER-AIDED DIAGNOSTIC SYSTEMS}

In the past decades, the literature has reported advances in computer-aided diagnostic systems that provide a more manageable solution. These propositions are geared towards the development of automated systems that are less prone to possible bias and that are often introduced in the process of diagnosis by medical experts, whose availability is low and sometimes do not exist in underserved communities [51 - 53]. A strong impulse has been seen in the literature to be given to the development of automated systems capable of assisting physicians in medical imaging tasks [48]. However, the presence of noise, masking structures, variability of biological shapes and tissues, and imaging system anisotropy make the automated analysis of medical images a hard task [42, 48, 51].

One of the best approaches to overcome the aforementioned challenges in automating medical imaging diagnosis is to exploit some kind of hypothetical information about the imaged structures. The information about the structures to be analysed can be anatomical knowledge about their typical appearance (such as shape and grey levels) and position or it can be statistical knowledge of their properties such as grey level of the tissues included in those structures. The images can then be classified using their morphological structure, colour, fractal and texture properties. Laws [54], transformed digital images to identify regions of interest and provided an input data set for segmentation and features detection operation. In the same study [54], operations such as thresholding, morphological analysis and texture detection were used in order to divide a digital image into individual objects to perform a separate analysis of each region.

Over the years, it has been reported that an automatic data analysis used for melanoma showed a higher diagnostic performance compared to an observation by a physician in terms of sensitivity (proportion of true positives), though lower in terms of specificity (proportion of true negatives) [29, 55 - 57]. (Fig. 1) highlights the frequently used evaluation metrics to determine the effectiveness of the diagnostic results. A common technique used for the foregoing automated data analysis is Dermoscopy or Epiluminiscence Light Microscopy (ELM). It is an in-vivo, non-invasive technique that in recent years has disclosed a new dimension of the clinical morphological features of Pigmented Skin Lesions (PSLs) using different light magnification systems [29]. Dermoscopy can be based on non-polarized light techniques that require liquid interface or direct skin contact or polarized light techniques [58]. For the past decades, dermoscopy has been a major tool used by the dermatologists to proffer early detection of skin cancer-related cases, thus lowering the number of excisions and consequently impacting the clinical management of PSLs [59]. Dermoscopy provides dermatologists with a higher accuracy for detecting suspicious cases than it is possible with popular practice of naked-eye inspection [56,60]. In addition, dermoscopy has been observed to aid the diagnosis of several other skin tumours such as Angiomas, Basal Cell Carcinomas, Cylindromas, Seborrheic Keratosis, and Hematomas, just to mention a few. In relation to the malignancy classification of melanocytic images, the ELM has been a great tool for dermatologists distinguish between life-threatening (malignant) and benign melanocytic lesions. The trend identified in the literature is the increase in the adoption of dermoscopy, primarily because of its ease of use, non-invasive approach, and slow adoption of other advance diagnostic technologies by many dermatologists. A recurring challenge, however, with the usage of dermoscopy is the complexity and subjectivity that characterize the interpretation of its results [41, 42, $57,61,62]$. The poor reproducibility of an analysis made with the usage of the technique is also a concern.

The development of automated diagnostic systems for skin lesion screening has provided promising reproducibility of diagnostic results, and an increase in the speed of diagnosis procedures [42, 63, 64]. In addition, the application of automated diagnosis has assisted to reduce the first-time diagnostic error which can be as much as $40 \%$ [49, 50] and mis-pathology cancerous analysis [65]. Proposed automated diagnosis techniques in the literature are essentially based on different diagnostic checklists and rules such as the Asymmetry, Border Irregularity, Colour (ABCD) variation and diameter of lesion [14], modified ABC-point list of dermoscopy [66], pattern analysis [67], ELM 7-Point checklists [15], and Menzies score [68]. 
$\rightarrow$ True Positive $(T P)$ - correctly identified subject against a particular criteria in a given set of subjects

$\rightarrow$ False Positive $(F P)$ - incorrectly identified subject against a particular criteria in a given set of subjects

$\rightarrow$ True Negative $(T N)$ - correctly rejected subject against a particular criteria in a given set of subjects

$\rightarrow$ False Negative $(F N)$ - incorrectly rejected subject against a particular criteria in a given set of subjects

$\rightarrow$ Sensitivity $\left(S_{n}\right)$ - statistical measurement of the percentage of proportion of true positive $S_{n}=\frac{T P}{T P+F N} \times 100 \%$

$\rightarrow$ Specificity $\left(S_{p}\right)$ - statistical measurement of the percentage of proportion of true negative $S_{p}=\frac{T N}{T N+F P} \times 100 \%$

$\rightarrow$ Likelihood Ratio Positive: $L R+=\frac{S_{n}}{1-S_{p}}$

$\rightarrow$ Likelihood Ratio Negative: $L R-=\frac{1-S_{n}}{S_{p}}$

$\rightarrow$ Positive Predictive Value: $+P V=\frac{T P}{T P+F P}$

$\rightarrow$ Negative Predictive Value $-P V=\frac{T N}{T N+F N}$

\begin{tabular}{|c|c|c|c|c|c|}
\hline & \multicolumn{2}{|c|}{ Ground Truth } & \multirow[b]{3}{*}{$=$} & \multirow[b]{3}{*}{$+P V$} \\
\hline & & \multirow{2}{*}{$\begin{array}{l}\text { Positive } \\
\text { True }+\end{array}$} & \multirow{2}{*}{$\begin{array}{l}\text { Negative } \\
\text { False + }\end{array}$} & & \\
\hline \multirow{4}{*}{$\begin{array}{l}\text { Test } \\
\text { Result }\end{array}$} & Positive & & & & \\
\hline & Negative & False - & True - & $=$ & $-P V$ \\
\hline & & $\|$ & $\|$ & & \\
\hline & & $S_{n}$ & $S_{p}$ & & \\
\hline
\end{tabular}

$\rightarrow$ Diagnostic Accuracy: $D A=\frac{T P+T N}{T P+T N+F P+F N}$

$\rightarrow$ Jaccard Index $(J)$ : Statistically compares similarity and diversity between Training data set $\left(\operatorname{Tr}_{D}\right)$ and Test data set $\left(T s_{D}\right)$

$$
J\left(T r_{D}, T s_{D}\right)=\frac{T r_{D} \cap T s_{D}}{\left|T r_{D}\right|+\left|T s_{D}\right|-\left(T r_{D} \cap T s_{D}\right)} \quad=\quad \frac{T P}{T P+F P+F N}
$$

$\rightarrow$ Dice Coefficient $(D S C)$ : Statistically compares similarity between Training data set $\left(\operatorname{Tr}_{D}\right)$ and Test data set $\left(T s_{D}\right)$

$$
\operatorname{DSC}\left(\operatorname{Tr}_{D}, T s_{D}\right)=\frac{2\left(T r_{D} \cap T s_{D}\right)}{\left|T r_{D}\right|+\left|T s_{D}\right|} \quad=\quad \frac{2 T P}{2 T P+F P+F N}
$$

NOTE:

(1)High Sensitivity and Specificity indicates high performance of a given method

2Likelihood Positive ratio greater than 1 with Likelihood Negative ratio less than 1 reflect the subject associate well with the specified criteria (such as classification or segmentation)

3 High Positive and Negative Predictive Value indicates high-performance of a given method

Fig. (1). Evaluation Metrics.

\section{SKIN LESION DIAGNOSTIC METHODS}

The literature generally shows that several methods for skin lesion diagnostic have been proposed to assist in the diagnosis of melanocytic lesions over the years. Prominent among these methods are Pattern Analysis for Microscopic Images (PAMI) [67], the ABCD criteria for macroscopic images [11], the ABCD rule of dermoscopy [14] for microscopic images, the ABCDE criteria [19] for macroscopic images, ABCDE rule [12], Glasgow 7-point checklists 
[13, 69] for macroscopic images, ELM 7-point checklists [70] for microscopic images, Menzies score [68] for microscopic images, 7 features for melanoma [71], Modified ABC-Point (MABCP) list of Dermoscopy [66] and Colour, Architecture, Symmetry, and Homogeneity (CASH) algorithm [72, 73].

The quantitative pattern analysis proposed by Pehamberger et al. [67], is based on detailed qualitative assessment of the numerous individual ELM criteria and typically requires a significant degree of formal training. Pattern analysis categorises specific patterns as global (reticular, globular, homogeneous, parallel) or local (pigmented network, dots, streaks, globules, blotches). The ABCD criteria proposed by Friedman et al. [11] employs a semi quantitative counting classification based on the evaluation of asymmetry of overall lesion shape, border irregularity, colour variation and diameter of lesion of minimum of $6 \mathrm{~mm}$. The ABCD rule of dermoscopy initially suggested by Stolz et al. [14] and later standardized in Argenziano et al. [52] uses similar measures in relation to the criteria defined by Friedman et al. [11], although different. Stolz et al. [14] have highlighted the key features of diagnosing a skin lesion. These features include asymmetry properties of the specific lesion (contour, colour and structures), unexpected border sharpness, colour variegation of 1 to 6 predefined colours (white, red, light brown, dark brown, blue-grey, black) and the inclusion of 5 differential dermoscopic structures (network, structure-less or homogeneous areas, branched streaks, dots, and globules). It was recommended that white colour should be only counted if the area is lighter than the adjacent skin. A Total Dermoscopic Score (TDS) of 4.75 or less signifies a benign melanocytic lesion, a score ranging from 4.8 to 5.45 denotes a suspicious lesion, and a TDS of more than 5.45 symbolizes malignancy.

Blum et al. [66] debated the need to simplify the criteria used in identifying malignant lesions. The simplified procedure termed as $\mathrm{ABC}$-point $(\mathrm{ABCP})$ list was formulated based on the concept of the ABCD rule of dermoscopy [14], Menzies score [68], and the modified ABCD rule by Kittler [56]. The simplicity of the ABC-point list for lesion evaluation is a great benefit, however, there exist some concerns about its sensitivity and accuracy. The CASH algorithm for dermoscopy proposed by Henning et al. [72] suggested that architectural order of lesion could be the most important features in distinguishing between malignant and benign melanocytic lesions. The comparative study carried out for CASH and state-of-the-art methods (Menzies score, ABCD rule of dermoscopy and ELM 7-point checklists) reported a comparable result [73].

Recently, a modified 4-points algorithm designed on the success of ABC-point list has been proposed, whose accuracy is similar to the CASH algorithm and similar in simplicity to the 3-point checklist [74]. The 4-point algorithm uses the existing criteria from the ABC-point list and adds another criterion by doubling the symmetry parameter criterion. The algorithm certainly looks promising, it might however be difficult to really ascertain the superiority of the algorithm over the ABC-point list and $\mathrm{CASH}$, given the small sample size on which it was tested. Moreover, the validation of this new algorithm is yet to be discussed in the literature.

The Glasgow 7-point checklists which was first discussed by Mackie [13] before being popularized [69] uses change in shape, size and colour of skin lesions as its major criteria, while lesion inflammation, crusting or oozing, sensory change or Pruritus and minimum diameter of $7 \mathrm{~mm}$ were used as minor criteria. While the Glasgow 7-point checklist has shown good adoption in clinical practice, there have been some concerns about its application in early lesion detection as well as its sensitivity and capability [15, 75]. Walter et al. [76] argued that the application of weighted revised version of the 7-points checklist, with a cut-off score of 4 rather than 3 performs considerably better and could thus be applied in general practice towards supporting recognition of clinically significant lesions as well as early identification of melanoma. ELM 7-point checklist proposed by Argenziano et al. [70] and endorsed in Malvehy et al. [61] uses 3 major criteria and 4 minor criteria, with each major criterion having a score of 2 points, whereas each minor criterion is given 1 point. A minimum total score of 3 is required for the diagnosis of melanoma. The major criteria used in the ELM 7-point checklists include atypical pigment networks, atypical vascular patterns and blue-white veil, while the minor criteria consist of irregular streaks, irregular globules or dots, irregular blotches and regression structures.

Contrary to the general adoption of the ABCD criteria for macroscopic image evaluation, there have been a number of concerns regarding the unwarranted biopsy because of misdiagnosis resulting from morphological overlap with dysplastic nevi. The relevance of the metrics such as Diameter (D) identifier from the ABCD criteria on melanoma having diameters less than $6 \mathrm{~mm}$ or on thin melanoma $(\leq 1 \mathrm{~mm})$ has also been questioned [19, $77-82]$. Whiteman et al. [83] recently validated this assumption by arguing that more melanoma deaths were attributable to thin tumours $(\leq 1 \mathrm{~mm})$ than thick tumours $(>4 \mathrm{~mm})$ in Queensland, Australia.

The discussions by Zaharna \& Brodell [84] as well as by Liu et al. [85] reasoned that change in lesion 
characteristics is one of the most important diagnostic features reported by patients towards early detection of melanoma. This inference further validates the choice of variegation in size, shape, and colour as major criteria for Glasgow 7-point checklists. The literature has thus seen various proposals for additional measures to complement the ABCD criteria. Fitzpatrick et al. [12] discussed the importance of expanding the ABCD criteria to ABCDE by studying the elevation (E) of lesion for early melanoma detection. The study by Rigel \& Friedman [86] and Thomas et al. [87] agreed on the need for the addition of identifier $\mathbf{E}$ to represent enlargement of lesion relative to other neighbouring lesion for optimizing the sensitivity and specificity of lesion diagnosis. Hazen et al. [16], equally suggested yet another similar criterion: $\mathbf{E}$ for evolutionary changes in lesion colour, including surrounding erythema and hyper-pigmented halo, size, pruritus, pain, surface characteristics, bleeding, symmetry and tenderness. To avoid misinterpretation of terms and to further ease distinguishing between melanoma and benign pigmented lesions, Abbasi et al. [19] proposed a more encompassing and simple criterion named evolving (E) to emphasize changes in lesion characteristics over time. Abbasi et al. [19] argued that the usage of $\mathbf{E}$ to represent lesion elevation (proposed by Fitzpatrick et al [12]) would be misleading since substantial elevation might not be apparent especially in early melanomas. In addition, there has been a recent discussion on the replacement of Diameter (D) in the ABCDE with lesion darkness (D) for early melanoma detection [26].

The Ugly Duckling (UD) sign introduced by Grob \& Bonerandi [88] has also been seen as a major insignia for spotting the possible presence of melanoma. The UD sign signifies suspected lesions that appear different from other benign lesions examined in the same patient. The validity of the UD sign was inspected in Grob et al. [89] as a useful tool for lesion expert towards second diagnosis opinion as well as for general population when performing selfexamination. The UD sign has influenced a number of research efforts towards early detection of malignant lesions. Hazen et al. [16] used the basis of UD sign to argue that it is beneficial to add another criterion of $\mathbf{F}$ (funny looking lesions) to the established ABCDE criteria. Similar argument to expand ABCDE to ABCDEF was recently discussed by Jensen \& Elewski [90] to improve patient self-screening examination, which has been applied as a useful tool for physicians in identifying worrisome melanocytic lesions. The progressive increase in letter addition to the established ABCD criteria has been seen to have contributed to the handling of edge case skin lesion diagnosis as highlighted above. However, it has also been sometimes criticized [91].

The 7 features for melanoma developed by Dal Pozzo et al. [71] include dermoscopic features that can aid screening of pigmented skin lesions. 4 of these features are considered major, each with the score of 2, while the remaining 3 features are classified as minor features with a score of 1 . The major features include regression erythema (whitepinkish depigmented area), radial streaming, grey blue veil, and irregularly distributed pseudopods. Inhomogeneity of two or more dermoscopic features, irregular pigment network and sharp margin all constitute the minor features. The 7 features for melanoma use a scoring system similar to ELM 7-point checklists however differ in the criteria.

Menzies et al. [68], discussed 11 features required to successfully diagnose a skin lesion. 2 of the features are tagged negative, while the remaining 9 are positive. The negative features include symmetry of patterns and singular colour (either of black, grey, blue, dark brown, tan and red). The positive features include blue-white veil, multiple brown dots, pseudopods, radial streaming, scar-like depigmentation, peripheral black dots/globules, multiple (5-6) colours, multiple blue or grey dots and broadened network. According to Menzies' score, a lesion is considered melanoma if it contains 1 or more of the positive features and none of the negative features.

In a bid to effectively recognize acral melanoma that does not exhibit the parallel ridge pattern, Lallas et al. [92] recently proposed irregular Blotch, parallel Ridge pattern, Asymmetry of structures, Asymmetry of colours, parallel Furrow pattern and Fibrillar pattern (BRAAFF) as a new checklist to improve diagnostic sensitivity of the acral melanoma. The BRAAFF checklist is composed of four positive of irregular blotches, ridge pattern, asymmetry of structures and asymmetry of colours and two negative predictors of furrow pattern and fibrillar pattern.

A comparative analysis made by Annessi et al. [93] on three of the algorithmic methods (Pattern Analysis, ABCD rule and 7-Point Checklists) using 198 equivocal melanocytic lesions revealed that Pattern Analysis was the most sensitive (85.4\%) and specific (79.4\%) in identifying Thin Melanoma (TM), followed by ABCD rule. Comparative performance of 4 dermoscopic algorithms (pattern analysis, the 7-point checklist, the ABCD rule, and the Menzies method) by non-experts for the diagnosis of melanocytic lesions lauded Menzies method for producing the highest diagnostic accuracy [94]. Over the years, dermatologists have been using both ABCD criteria as well as the ABCD rule as a standard for classifying Pigmented Skin Lesion (PSL) as benign, suspicious or life threatening (malignant) primarily because of their simplicity and efficient approach $[66,95,96]$. 
It is important to note that the rules that target microscopic (dermoscopic) images differ from that of macroscopic (clinical) images even in the areas where similar terms are shared. The ABCD criteria [11] for macroscopic images differ from ABCD rule of dermoscopy [14] for microscopic images. The identifier 'B' in the study of Friedman et al. [11] refers to border irregularity, whereas the same identifier reflects border sharpness in the study of Stolz et al. [14]. In addition, identifier ' $\mathbf{D}$ ' refers to differential structure for microscopic images, whereas it generally represents diameter greater or equal to $6 \mathrm{~mm}$ in macroscopic images. These consequently filter down to the popular ABCDE criteria [19] and likewise the ABCDE rule [12]. Similarly, the different criteria highlighted above for both macroscopic bound Glasgow 7-point checklists discussed by Mackie \& Doherty [69] and the microscopic bound ELM 7-Points checklists proposed by Malvehy et al. [61] showed a clear distinction between criteria and checklists used in both the procedures.

Most articles in the literature generally use either of aforementioned methods in speculating lesion classifications. This speculation is often accompanied with the assumptions that malignant moles are pigmented. However, there has been an increase in the reports of non-pigmented skin tumours [97 - 100]. This suggests a more careful approach and systems that need to be instituted to resolve such cases to curtail potential fatality. It should also be noted that some types of melanoma (amelanotic) have been reported to be clinically and dermoscopically featureless resulting in misdiagnosis during both clinical examination and dermoscopy screening [101].

\section{HOMOGENOUS SKIN LESION DIAGNOSTIC PROCEDURES}

To achieve a reproducible diagnosis, the research community has frequently used a number of standard automated procedures for improved diagnosis of Pigmented Skin Lesions (PSL) and its non-pigmented counterpart. These procedures include skin lesion image acquisition and preprocessing; lesion segmentation from surrounding healthy skin, extraction of selected features and classification of skin lesions.

\subsection{Skin Lesion Image Acquisition and Preprocessing}

Results of diagnosis reported in the literature have been judged to be highly dependent on the volume and quality of images used [29, 102, 103]. Often, variations in devices used in capturing lesion images and conditions under which these images are acquired have been observed to adversely affect the results of automated skin lesion diagnosis. In the time past, the source of image data for lesion screening was colour slides. However, over the past decades, it has been proven that quality and accurate diagnosis can be achieved using digitized lesion images [104 - 106]. The two predominant dermatological image types are macroscopic (clinical) and microscopic (dermoscopic) images. While the use of digitised dermoscopic images is on the increase, some reports have argued that pertinent distinguishing image features (diminishing textures and pored) are easily examined using macroscopic images rather than under dermoscopic images [107].

The literature has reported several imaging techniques that could assist in the acquisition and screening of skin lesion images [108 - 110]. One of such popular technique is dermoscopy which provides in-vivo, non-invasive imaging of skin lesion using different light magnification systems [14, 17, 45, 52, 56, 58 - 61, 66, 67, 111 - 131]. Other notable imaging techniques include digital photography [108, 110, 131 - 134], radiography [110, 135], confocal microscopy $[80,108,115,133,136-148]$, tomography such as computed tomography, positron emission tomography, photoacoustic tomography, optical coherence tomography and magnetic resonance imaging [108, 110, 149 - 172], ultrasound imaging [108, 110, 173 - 180], multispectral imaging [108, 181, 182] and thermal imaging (thermography) [183 - 186]. A review of non-invasive imaging techniques was recently discussed by Menge \& Pellacani [109], detailing the application of various imaging techniques and the accompanying shortfalls. Arguably, due to slow adoption of advances in diagnostic technology by many dermatologists, the trend noticed in the literature is a growing increase of the usage of dermatoscopy (Dermoscopy). Recently, the usage of dermatoscope with mobile phone camera has also been discussed in some studies for making acquisition of lesion images easier [28, 187, 188]. Reflectance microscopy has equally been dubbed to give good result against the light coloured melanoma lesions [80].

While each individual imaging method has produced a promising result in the screening of lesions, there has been a rise in the mixture of imaging methods to enhance sensitivity, specificity and accuracy of lesion screening [151, 152, 189, 190]. This is further validated by Mohr et al. [191] and Reinhardt et al. [153] and recently by Bourgeois et al. [170] that the combination of Positron Emission Tomography and Computed Tomography (PET/CT) revealed a better sensitivity in staging of malignant tumours. Wang et al. [173] equally argued that integrating photoacoustic tomography with ultrasound has yielded a better specificity when compared to when either method was used in isolation. The 
combination of confocal and photo thermal microscopy was recently discussed by He et al. [192] for noninvasive and label free 3-D imaging of melanoma. A good review was conducted by Dancey et al. [110] to compare various techniques used in imaging melanoma, and consequently recommended a choice of imaging techniques based on their applicability, accuracy and cost. In the review [110], it has been suggested that ultrasound imaging (ultrasonography) is the most effective mode of screening in the absence of sentinel lymph node biopsy. A similar view was shared by Xing et al. [189] during the comparison made between the usage of ultrasonography, CT, PET and PET/CT in staging and surveillance of melanoma patients.

In image processing, commonly used colour spaces include Red-Green-Blue (RGB and sRGB), Commission Internationale de l'Eclairage (CIE L*a*b, CIE L* $\mathrm{u}^{*} \mathrm{v}$ and $\mathrm{CIE} \mathrm{X}^{*} \mathrm{Y}^{*} \mathrm{Z}$ ), Luma plus chrominance $\left(\mathrm{Y}^{\prime} \mathrm{CbCr}, \mathrm{Y}^{\prime} \mathrm{PbPr}\right.$, Y'UV and YIQ) and Hue-Saturation-Intensity-Value-Luminance (HSI, HSV/B and HSL). Most digitized lesion images are commonly generated as RGB. However, because of device dependency of RGB colour space, digitized lesion images are often converted to greyscale or blue channel for single channel (scalar) processing in order to represent the intensity of the image. In a bid to ease the accuracy of classification, Dobrescu et al. [48] converted each image used in their study to 256 grey levels image of the same size as a form of preprocessing of the image in Hue Saturation Value (HSV) colour space. Multichannel (vector) processing can equally be used to take advantage of the original colour information of the lesion. The main challenge, however, with the use of vector images is the computational requirement. Gómez et al. [193] argued that it is implausible that a particular colour space is optimal across different dermoscopic images acquired via different systems, even though the images have similar prognosis. Some reports [194 - 196], however, revealed that CIE $\mathrm{L}^{*} \mathrm{a} * \mathrm{~b}$ colour space produced a convincing result compared to its counterparts (CIE $\mathrm{L} * \mathrm{u} * \mathrm{v}$ and $\mathrm{CIE} \mathrm{X}^{*} \mathrm{Y}^{*} \mathrm{Z}$ ) and the popular $\mathrm{YCbCr}$ colour space when performing preprocessing of multichannel microscopic lesion images.

The term preprocessing in lesion image diagnostic procedures usually encompasses lesion image enhancement, image restoration with neighbourhood pixels and artefact removal [197]. The conditions surrounding the acquisition of lesion images generally influence possible discriminating features that can be extracted from such images for the purpose of automated diagnosis. Rahman et al. [198] reasoned that retrieval and the classification tasks of lesion could be challenging when images collected from separate data sets are captured by different devices under varying conditions (such as lightening). This creates a non-uniform illumination pattern, thus confusing diagnostic procedures. Colour calibration of image acquisition device has been one of the approaches proposed in the literature to resolve such challenges [199 - 205]. Low contrast of lesion images could also make isolation of lesion a very difficult task [206]. Abbas et al. [195] proposed enhancing lesion image contrast by adjusting and mapping the intensity values of the lesion pixels in the specified range in CIE L*a*b colour space. One major flaw of contrast enhancement is over amplification of noise in the region having relatively small intensity range. The use of Contrast Limited Adaptive Histogram Equalization (CLAHE) might be applied to address such limitations [207, 208]. (Figs. 2 and 3) respectively illustrate the normal and filled histogram of the image shown in (Fig. 4 and 5) shows an equalized histogram of the same image in (Fig. 4) for better noise removal resolution.

A major hindrance to a successful diagnosis in medical skin imaging is the presence of artefacts, typically referred to as noise. Artefacts such as hair shaft (Figs. 6 and 7), dermoscopic gels, thin blood vessel, shadows, ruler marking, specular reflections, vignetting and air bubble can confuse diagnosis and impede achievement of better accuracy in automated diagnosis process [107, 209 - 211]. To resolve the challenges posed by these artefacts, the literature report the use of a number of approaches which consist primarily of artefact detection (Fig. 5) and subsequent artefact removal (Fig. 4). Methods used for aiding the detection of artefact include filtering (curvilinear matched, Prewitt, Gaussian, median and bilateral), derivative of Gaussian, morphology operations (closed based top hat) and anisotropic diffusion. Filtering is a popular method to smooth a lesion image before detecting artefacts. Bilateral filtering has been seen to perform very well amongst other types of filtering because of its edge-preserving smoothing operation on the lesion images, especially on microscopic images [194]. Karkunen-Loéve is another method often used to preserve artefact edges during image smoothening. Prominent among the artefact removal methods is the linear interpolation [212, 213]. This was popularized in the demonstration of the system named DullRazor that was proposed by Lee et al. [213] to remove hair artefacts from a given lesion image. Other commonly used artefacts removal methods include inpainting (partial differential equation, exemplar-based, fast marching) [214 - 219] and region growing [107, 220]. A promising method called lacunarity algorithm which is a measure of transitional invariance for computing aspects of patterns exhibiting scale-invariant changes in the structure was equally proposed by Gilmore et al. [96] to avoid the need for a more sophisticated method. 
The hair shafts and ruler marking appear to be the most common artefacts reported in the literature [210, 214,221 226]. In our study, we observed that much effort has been given to the removal of hair shaft and ruler markings from lesion images [107, 209, 210, 213, 214, 220, 225, 227]. An excellent review by Abbas et al. [55] discussed a comparative study of the state-of-the-art algorithms for automatic detection of hair and restoration, vis-à-vis their applicability to the texture-part of lesion images. A novel algorithm comprising of morphological and fast marching schemes was also suggested in a study [55]. Similar procedure of using fast marching inpainting was discussed by Okuboyejo et al. [194] towards improving the speed of preprocessing of dermoscopic lesion images. Toossi et al. [228] also suggested the usage of multi-resolution coherence transport inpainting based on wavelet-based structure for the removal of hair artefacts in dermoscopic images. The algorithm proposed in a study [228] combines simple coherence transport inpainting with a wavelet decomposition and reconstruction method in an iterative and multi-resolution structure.

\subsection{Lesion Image Segmentation}

The successful segmentation of skin lesion from the healthy surrounding skin is a pertinent requirement for a workable lesion diagnostic process. The analysis of a number of the dermoscopic features (asymmetry, border sharpness) and clinical features (asymmetry, border irregularity) is only as accurate as the estimated lesion boundary. The variations in human interpretation of manual lesion boundary tracing have equally influenced the automation of lesion segmentation procedure [229, 230]. According to the literature, the estimation of lesion border by dermatologists has been reported to depend upon higher-level knowledge, leading to poor reproducibility of segmentation results [231]. However, Silletti et al. [232] argued that with exception of the Fuzzy C-Means (FCM), some state-of-the-art automatic segmentation methods performed poorly when compared with segmentation carried out by expert dermatologists. In Fig. 8), an example is shown on a segmented lesion image that has been localized from its surrounding healthy skin.

The segmentation task has sometimes been referred to as one of the most difficult tasks in medical imaging. Among other concerns, the difficulty can be attributed to low-contrasts surrounding the skin, fuzzy borders, the existence of artefacts and irregular structures characterizing lesion images [48, 65, 211, 233 - 235]. Readers can refer to the previous section detailing preprocessing techniques for image contrast enhancement and removal of occluding artefacts typically found in both macroscopic and microscopic images. Some reports in the literature have equally suggested that tumour areas manually extracted by dermatologists have been discovered to be sometimes characterized with inconsistency [232, 236 - 238], validating the need for an automated lesion segmentation approach that can aid reproducibility of results. In recent times, the literature has seen a great improvement in automating lesion image segmentation from the surrounding healthy skin parts for the purpose of achieving automated diagnosis of such lesion images. However, Chang et al. [239] argued that it is impractical to perform fully automatic segmentation on all skin lesion images due to reasons such as complexities surrounding acquisition of lesion images.

Most segmentation approaches incorporate some forms of image preprocessing to reduce or eliminate image noises such as air bubbles, ruler marking, hair shafts that could confuse segmentation. An example of this is the application of combined spline and B-spline by Abbas et al. [240] to enhance the quality of dermoscopic images before segmentation. The Karkunen-Loéve Transform (KLT) also known as Principal Component Analysis/Transform (PCA/T) was used to enhance the edges of the lesion image for better segmentation result in some studies [20, 57, 193, 241, 242]. The top-hat and bottom-hat transformations were applied in a study [243] to maximize the contrast of lesion images in order to achieve a comparable lesion segmentation using ensemble methods. The literature has chronicled the numerous lesion localization (border detection) approaches that can help to segment pigmented skin lesion from the neighbouring region in an automated mode. A number of lesion segmentation algorithms (including edge based, region based and thresholding) have equally been proposed in the literature. In the course of our study, we observed that most of the reported segmentation methods in the literature are based on the colour information of the lesion being examined arguably due to the simplicity of the representation of lesion colour properties. Some reports [244 - 249] have equally used texture properties of skin lesions to estimate lesion boundaries. Commonly adopted texture feature methods used in segmenting skin lesion areas include Grey Level Co-occurrence Matrix (GLCM) [245], Gabor functions [248], Laws texture energy masks [54], Markov Random Field (MRF) models [246, 250]. Glaister et al. [244] equally proposed a texture oriented lesion segmentation algorithm called Texture Distinctive Lesion Segmentation (TDLS). The TDLS algorithm uses joint statistical information to characterise skin and lesion textures as representative texture distributions. Maeda et al. [251] combined colour and texture features in a proposed Fuzzy-based hierarchical algorithm to achieve a perceptual segmentation of dermoscopic lesion images. 
The edge based segmentation methods essentially use metadata about edges of a given lesion image in addition to related post-processing techniques to estimate the boundary of a lesion [219, 234, 252, 253]. The implementation of edge-based lesion segmentation often requires the use of the established edge operators such as Canny [254 - 256], Prewitt [257], Sobel [258], Kirsch [259] and Laplacian of Gaussian (LOG) [260]. An edge-based segmentation method based on dynamic programming using CIE L*a*b* colour space was proposed by Abbas et al. [233, 234]. However, the major challenge in the application of dynamic programming is its inability to accurately detect outline of lesion in scenarios where areas belonging to the lesion are divided into multiple tumours.

Region-based methods use a seed-based approach that groups the regions according to common image properties and relative information of the neighbouring pixels [236, 261 - 267]. Popular region-based methods include FuzzyBased Split and Merge (FBSM), J-Image Segmentation (JSEG) [262, 268], Statistical Region Merging (SRM) [269, 270], Iterative Stochastic Region Merging (ISRM) [266] and watershed [226, 271]. At this juncture, we would like to state that though there exists a similarity between edge-based lesion segmentation and region-based lesion segmentation, but both are different. Essentially, region-based segmentation methods require closed boundary to properly estimate lesion borders, whereas such requirement is not essential for edge-based segmentation. It has been argued that region-based lesion segmentation sometimes leads to over-segmentation [272]. Over-segmentation can occur when the interior of a lesion exhibits multi-coloured areas. Many advances have been recorded in the literature to resolve the aforementioned challenges, thus yielding effective region-based lesion segmentation. Ma \& Tavares [273] recently proposed an algorithm built on deformable model methods to define speed function on the lightness, saturation, and colour information of a given dermoscopic image in order to estimate its lesion boundary. Geometric deformable models have been posed to implicitly represent the moving curve evolution in a way that helps to obtain desirable features (such as regions and the boundaries of the skin lesions) for shape and colour analysis simultaneously [273]. Similarly, a saliency-based segmentation method was proposed by Ahn et al. [274] via measurement of sparse reconstruction errors against image backgrounds to estimate contrast discrimination between the lesion part of a given image and the surrounding healthy skin. Saliency-based segmentation techniques help to resolve the problem of target localization, such as the difficulties in segmenting lesion image with multi-coloured objects, as well as lesion images having similar colour between the foreground and background region. The approach proposed by Olugbara et al. [275] utilized a perceptual colour difference saliency with morphological analysis to achieve a compelling segmentation result of lesions. A good future research would be to investigate how saliency segmentation can be used on lesion images with multiple saliency-regions.

In general, contour segmentation methods can be either region-focused or edge-focused. Edge related contour segmentation typically applies edge detectors to estimate stopping function for terminating contours at distinct edges, making it unusable for fuzzy edges. Region related contour segmentation computes region energy based on the mean value of lesion image intensity and consequently uses global image information to terminate contours even for indistinguishable edges. Most contour-oriented lesion segmentation techniques are more or less similar to their regionbased segmentation method counterparts. The similarity is due to the usage of seed-based approach in categorising image region according to the common criteria between both methods. Contour oriented segmentation is often referred to as snakes [219]. Frequently used contour-oriented methods include adaptive snake, robust snake [276], Gradient Vector Flow (GVF) snake [277, 278], Mean-Shift based GVF [279 - 282], level set [263, 264, 276, 283, 284] and radial search [285, 286]. Mete \& Sirakov [287] discussed enhancing active contour model with optimum parameters, including high boost filtering to achieve comparable segmentation results with other state-of-the-art segmentation methods. Similarly, Ivanovici \& Stoica [288] suggested that a diffusion model for colour images can be used as external energy for active contours in order to achieve lesion segmentation by independently computing diffusion at various scales. The study reported by Yuan et al. [284] equally introduced a region-fusion-based segmentation framework by combining graph partitioning methods with chan-vese level set to achieve a comparable lesion segmentation result. In addition, Kasmi et al. [289] recently proposed a geodesic active contour (GAC) based lesion segmentation method that employs an automatic contour initialization close to the actual lesion boundary. This approach was lauded to address the sticking challenge at minimum local energy spots typically caused by noise artefacts such as hair shaft. Fig. (5) displays an example of result after applying contour-based techniques called Line Segmentation Detection (LSD) [290] on an image in order to segment occludinh hair artefacts. 


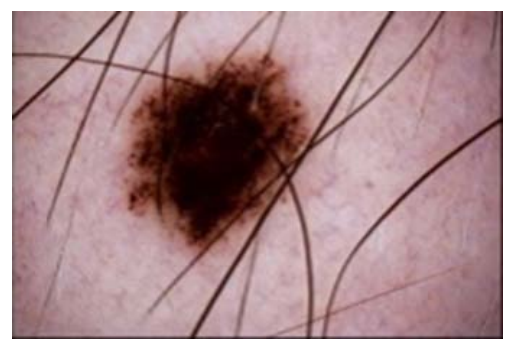

Fig. (2). Original Image.

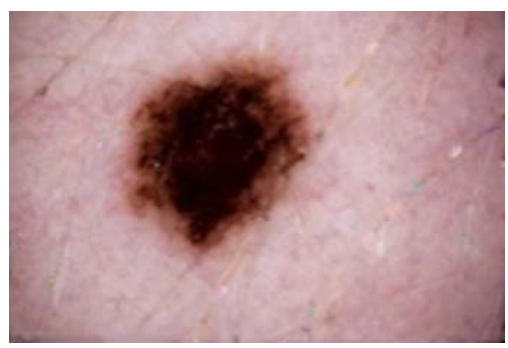

Fig. (3). Preprocessed.

Fig. (4). Histrogram.
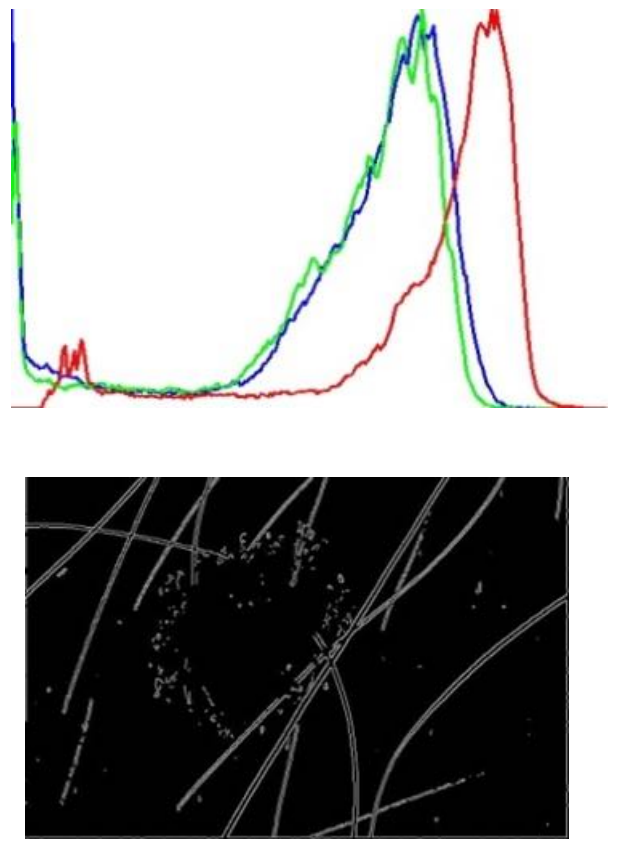

Fig. (5). Noise image.

Fig. (6). Equalised Histrogram.

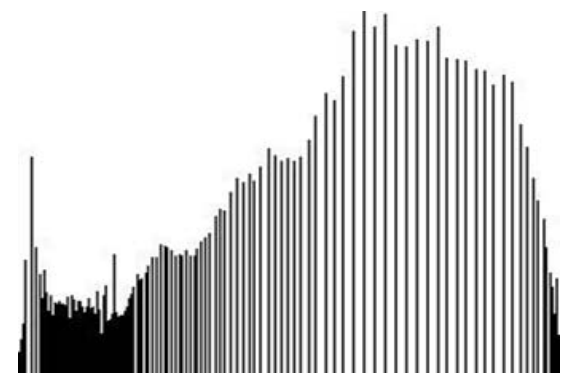




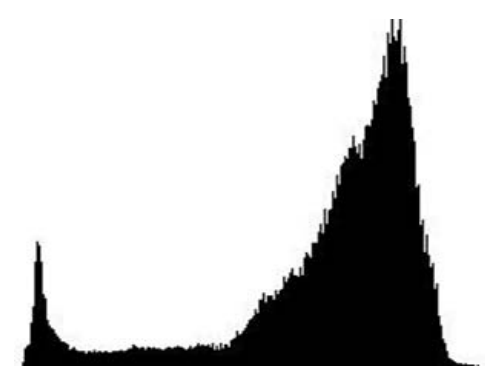

Fig. (7). Filled Histrogram.

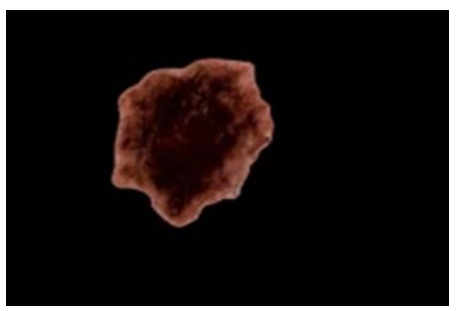

Fig. (8). Segmented Image.

Given a grey level co-occurrence matrix GLCM $\rightarrow C_{i, j}$

Entropy - measures the unpredictability of grey level distribution

$$
\sum_{i} \sum_{j} C_{i, j} \log \left(C_{i, j}\right)
$$

Energy - measures the sum of squared elements in GLCM. It is also referred to as angular $2^{\text {nd }}$ moment

$$
\sum_{i} \sum_{j} C_{i, j}^{2}
$$

$\rightarrow$ Contrast - measures the local variation in the greylevel co-occurrence matrix

$$
\sum_{i} \sum_{j}(i-j)^{2} C_{i, j}
$$

Correlation - measures the joint possibility of specified pixel points occurrence

$$
\sum_{i, j=0}^{k-1} C_{i, j}\left[\frac{\left(i-\mu_{i}\right)\left(j-\mu_{j}\right)}{\sqrt{\sigma_{i}^{2}} \sigma_{j}^{2}}\right]
$$

homogeneity: measures closeness of the distribution of elements in GLCM, relative to its diagonals

$$
\sum_{i} \sum_{j} \frac{C_{i, j}}{1+|i-j|}
$$

Fig. (9). Textual feature descriptors.

The thresholding technique is adjudged to be the most adopted approach in the literature for lesion segmentation using the computation of image intensity [198, 206, 207, 221, 240, 247, 291 - 299]. The discussion of thresholding in this section addresses segmentation of the lesion image rather than its usage in preprocessing of images. Typically, thresholding technique involves a non-linear process of producing a binary image such as by assigning two levels to pixels below or above a specified threshold value. Thresholding can be categorised based on the parameter usage as either parametric or non-parametric. Parametric thresholding uses a set of parameters to control fitness of the model while non-parametric thresholding estimates thresholds by optimizing objective functions such as variance-based functions (cluster variance) or entropy-based functions (cross entropy). Non-parametric thresholding can be further 
categorised either as global thresholding based on whether thresholding is performed on an entire lesion image using a single value or as local thresholding if a lesion image is partitioned into sub images, with each image region having their respective threshold value. Most thresholding approaches discussed in the literature are seen to be global. Global thresholding can be further classified as either a point dependent, if the threshold value is determined using grey level of each pixel of the lesion image or as a region dependent if the threshold value is determined from the local property in the neighbourhood of each pixel of the lesion image. According to the literature, the implementation of a particular thresholding technique could be based on region entropy, local lesion property, histogram shape, spatiality, image attribute similarity as well as clustering [300]. Notable thresholding techniques reported in the literature for lesion image segmentation are based on popular thresholding algorithms such as Otsu [294, 301 - 306], type-2 fuzzy logic [297, 307], random walker [308], Kapur [304, 305, 309], Kittler [310], Ridler [311] and Sahoo [312].

In relation to image processing, clustering is sometimes referred to as a multidimensional extension of thresholding. Clustering based lesion segmentation techniques generally adopt unsupervised erudition to identify a finite set of clusters to which image pixels would be grouped. Notable clustering methods vis-à-vis skin lesion image segmentation include fuzzy c-means (FCM) [20, 238, 313, 314], k-means [193, 215, 315 - 317], g-means [248], density-based spatial clustering [229, 230, 318 - 320], grid-based spatial clustering [318], wavelet transform [313, 321, 322] and Markov random field (MRF). Recently, Khalid et al. [321] proposed an implementation of dynamic wavelet transform based on Cohen-Daubechies-Feauveau Biorthogonal to segment lesion images. The Independent Histogram Pursuit (IHP) algorithm proposed by Gómez et al. [193] revealed the possibility of segmenting lesion images using K-means clustering technique that is agnostic of colour space of the image and the number of image bands. Kockara et al. [323] used a graph clustering segmentation technique based on the soft kinetic data structure to estimate lesion border of microscopic images and consequently segmenting the lesion images. Mete el al [230]. proposed a border-driven density-based framework to identify skin lesion border by expanding regions at borders of a cluster. This approach was further improved [229] by removing preprocessing dependency. Castillejos et al. [313] proposed an ensemble of clustering based methods to segment lesion image by exploring all colour channels. Melli et al. argued in a comparison study [324] that mean shift clustering can outperform other colour clustering algorithms (median cut, k-means and fuzzy-c means) in terms of sensitivity and specificity as the number of clusters increases. Kockara et al. [325] argued that density-based clustering produces a high precision and recall rate, with low border error when used to estimate lesion image border leading to a superior result when compared to the FCM. Recently, Lemon et al. [320] advanced the usage of density clustering by proposing a skin lesion border detection method based on web computing language (WebCL) parallel density. The approach [320] takes advantage of Graphical Processing Unit (GPU) computing power of web browsers to provide quick skin lesion border detection for dermoscopic images.

The usage of morphology and statistical information, together with clustering based approaches has equally been reported in the literature. This technique involves the use of morphological features to estimate discontinuity in lesion image structures [193, 261, 326 - 328]. Popular morphological based clustering methods include normalized cut [328], Principal Component Analysis (PCA) [20, 57, 193, 242], linear component analysis (LDA) [329], median cut [324] and grabcut [207].

There has been a growing need to advance lesion segmentation via machine learning system. This has led to the application of several expert systems to aid segmentation of lesion images from surrounding healthy skin [238, 322, 327,330 - 332]. Application of machine learning for lesion segmentation typically involves the use of expert systems to process small areas of an image for the purpose of classification. Subsequently, the network system then classifies different areas of the image based on classifications recognized by the system. Xie et al. [331] proposed a lesion segmentation algorithm for dermoscopic images by combining Self Generating Neural Network (SGNN) with Genetic Algorithm (GA). Frequently used neural network systems recorded in the literature for lesion segmentation include Radial Basis Function (RBF), Back Propagation Network (BPN), Extreme Learning Machine (ELM), Markov Random Field (MRF) [250, 327], Wavelet Network (WN), Multi-Layer Perceptron (MLP) [326] and Bayesian [327].

The literature has equally reported attempts to use ensemble of methods to improve lesion image segmentation, such as using multiple thresholding algorithms, multiple clustering approaches, region-based segmentation with neural networks or combining thresholding with region-based methods [20, 226, 240, 243, 295, 303 - 305, 313, 315, 331, 333 335]. In a study [48], variable threshold (based on binary imaging) and contour extraction were used to detach the shapes of the masses before determining border outline of the lesion. A study [51] utilized Laplacian filter to localize the lesion area, while zero-crossing algorithm helped the author to perform automatic outline of the lesion border. The study [41] used both pixel-based and region-based approaches to develop an algorithm, which is referred to as 
Dermatologists-like Tumour Area Extraction Algorithm (DTEA) to discriminate the actual tumour area from the surrounding skin. The combination of statistical clustering of the lesion colour space and hierarchical region-growing algorithm was used in a study [336] as a segmentation technique. In another study [65], segmentation was performed using a combination of bimodal histogram based on fuzzy sets region growing. Three segmentation algorithms (global thresholding, dynamic thresholding and a 3D colour clustering concept), together with fusion strategy were used [337] to obtain binary segmentation of the lesion. Pennisi et al. [272] proposed a fully automatic lesion segmentation procedure that combined edge based method (Canny) with region-based method (Delaunay triangulation) to resolve the segmentation of lesion areas.

A number of good reviews have discussed and compared notable automated lesion segmentation approaches. In the comparison study conducted by Mete \& Sirakov [287], it was argued that density-based clustering performs better than Active Contour Models (ACM) when segmenting noisy lesion images. However, the ACM was adjudged to perform better when used with an optimum parameter. Celebi et al. [338] used a normalized probabilistic rand index to evaluate five different lesion segmentation approaches which include Orientation-Sensitive Fuzzy C-means Method (OSFCM) [314, 339], Dermatologist-like Tumour Extraction Algorithm (DTEA) [40, 41], mean shift clustering method [324], modified J-image Segmentation (JSEG) method [262, 268], and Statistical Region Merging (SRM) [269]. The evaluation reported the prowess of SRM as well as the consistency of DTEA across varying lesion image types. Recently, a comprehensive lesion border detection was surveyed by Celebi et al. [340] and some of the unresolved border detection issues were discussed. The latest review by Oliveira et al. [221] on computational methods for segmenting lesion images discussed several lesion boundary techniques. In the review, edge-based segmentation for lesion image was discouraged due to the fact that edge-based segmentation doesn't consider closed boundary, and as such may produce segmented images that are not completely closed. The comparative evaluation carried out by Mendonça et al. [276] adjudged adaptive thresholding to produce the most favorable automatic segmentation of lesions, while robust snake was said to have produced a more consistent result. Silveira et al. [283] however, argued that adaptive thresholding as well as vector-valued Chan-Vese level set [341] yielded the least satisfactory result in their comparative work. In the same study [283], a proposed extension of Chan-Vese level set, called ExpectationMaximization Level Set (EM-LS) method which uses probability density functions to model lesion intensity assumptions, was observed to produce robust skin lesion segmentation result. This inconsistency in the reported evaluation could be attributed to several factors, including varying data set used as well as different comparative evaluation metrics.

It is sometimes difficult to properly analyse different automatic border detection methods for lesion images without subjective opinions resulting from the evaluation of the parameters used. Celebi et al. [338] suggested a Normalized Probabilistic Rand Index (NPRI), which takes into account the variations in the ground-truth images when evaluating different skin lesion segmentation methods. In the study [338], NPRI was adjudged to outperform the commonly used exclusive OR (XOR) measure. Garnavi et al. [342] equally proposed a weighted performance index for objective evaluation of five automated border detection methods for dermoscopy images. The weighted index was computed from six standard evaluation metric (sensitivity, specificity, accuracy, precision, border error, and similarity). The approach was further optimized in a study [343] by applying constrained non-linear multivariable optimization method in the computation of the weights.

We observed that most reported work in the literature on lesion image segmentation has been on microscopic (dermoscopic) images. From the literature, only a few efforts have been recorded in the usage of clinical (macroscopic) images for evaluating automatic lesion area segmentation approaches [249, 261, 298, 306, 335, 344]. This arguably could be attributed to the increased adoption of dermoscope in the evaluation of skin lesion images. Cavalcanti et al. [335] proposed an Independent Component Analysis (ICA) based ensemble methods to estimate lesion areas from healthy surrounding skin. In the same study [335], ensemble of thresholding and level set methods were then applied for the actual lesion boundary detection and segmentation thereof. Recently, Flores \& Scharcanski [249] proposed an unsupervised dictionary learning method called Unsupervised Information Theoretic Dictionary Learning (UITDL) for estimating lesion area in macroscopic images.

The analysis made from the reports discussed in the literature suggests that a number of past works in the lesion segmentation efforts have focused on the development of algorithms based on colour information in the non-uniform space. There's however a growing need towards optimizing segmentation algorithms in order to reduce computation time. In a bid to resolve the later, Okuboyejo et al. [207] proposed a Fast Image Segmentation (FIS) method based on the notable Contrast-Limited Adaptive Histogram Equalization (CLAHE), morphological operations, thresholding and 
grabcut techniques to localize lesion area from the surrounding healthy skin in a recorded time.

While most of the segmentation techniques discussed above yielded considerable promising results, the main problem with most of the approaches is that the computer-extracted regions sometimes were often smaller than the dermatologist-drawn ones (segmentation ground truth). Consequently, this makes some areas surrounding the tumour which are important features in the diagnosis to be excluded from the subsequent analysis [96, 103]. There are indications from the literature that many existing segmentation systems have high sensitivity rates towards effective diagnosis, they however experience high computing time [41, 57]. The usage of more than one algorithm for segmentation is one of the major causes of the non-realistic computing time as highlighted in a study [57]. It has also been noted that numerous past works have focused significantly on developing algorithms based on colour information in non-uniform colour spaces (disregarding the role of textural information). This has been reported to sometimes yield unsatisfactory segmentation results [234]. Another unresolved concern is the development of clinically oriented evaluation methods that can adapt variations in multiple manual borders [340]. While future research most likely would continue to use the mixture of algorithms due to increasing success rate of such approaches, more efforts should be made towards optimizing these algorithms to reduce their computing time. We would also like to suggest that the comparison of segmentation algorithms should be done on the same set of lesion images to ensure proper accuracy measure.

\subsection{Feature Extraction}

The primary objective of feature extraction is to quantify the macroscopic (clinical) or microscopic (dermoscopic) signs used in determining the malignancy of a skin lesion by a set of finite numerical features. Isolation of discriminating features in a given lesion image is an essential step towards effective automated lesion image classification. However, the vast variety of dermoscopic images and highly subjective definition of features characterizing these images have made the extraction of needful features a tedious task $[40,64,96,345,346]$. Skin distortion caused by bacterial and viral skin infections also makes analysis of features very difficult. In addition, variables such as body location, subject parameters (age), imaging parameters (lightening or camera), and direction from which lesion image is viewed and illuminated, greatly influence the resulting features that can possibly be extracted for classification purpose. These challenges typically add some overheads towards achieving automatic screening and diagnosis of medical images, especially skin lesions.

There have been numerous attempts reported in the literature to solve some of the above-mentioned challenges. One of the best approaches to address these aforementioned challenges in automating medical imaging diagnosis is to simplify the objective of the analysis and exploit some kinds of hypothetical information about the image structures. The information about the structures to be analysed can be anatomical knowledge about their typical appearance (shape, grey levels and position) or statistical knowledge of their properties (such as the greylevel of the tissues included in those structures). The images can then be classified using their morphological properties such as colour, shape, edges and texture.

The familiarity and potential discriminating power of the previously mentioned lesion diagnostic algorithm methods (such as $\mathrm{ABCD}$ rule of dermoscopy, $\mathrm{ABCD}$ criteria and Pattern analysis) have led to their usage in feature quantification. These feature descriptors can be dermoscopic, clinical or simply morphological in nature. Most reports discussed in the literature derived various discriminating lesion feature descriptors from these diagnostic algorithms, especially from the $A B C D$ rule for dermoscopic images and $A B C D$ criteria for clinical images. Feature descriptors used in the discrimination of skin lesion can favourably be categorised mostly as either photometric or textural. In the literature, it has been observed as common practice to use an amalgamation of various descriptors for lesion discrimination. Essentials features with corresponding discriminating properties used across the reviewed literature has been listed in Table $\mathbf{1}$.

Photometric has been seen to constitute the majority of the properties used in the literature when examining descriptors that could be used in classifying skin lesions. Photometric features include colour, island of colour, colour homogeneity \& colour histogram etc. Barata et al. [64] argued that photometric features, when used with textual descriptors, yield a good result, however, the photometric features were observed to outperform the textual features if used in isolation. Stoecker et al. [347] equally suggested in his work that greater separation of melanoma from benign lesions is achieved using relative colour than using absolute colour.

Texture-based descriptors are yet another set of features that reflect the structural pattern of lesion surfaces 
irrespective of the colour or illumination characterizing the lesion. Texture descriptors can be categorised as spatial frequency based, statistical based, geometric based or model based. Spatial frequency based texture features are frequently associated with wavelet and ridgelet transformations. Statistical based descriptors include co-occurrence matrices and Fourier properties for describing lesion's local neighbourhood properties. Geometric features describe skin lesion characteristics that include shape, border, symmetry, area, diameter, variance, perimeter, circularity and anisotropy. Model based textual descriptors are frequently associated with fractals and Markov random fields. Due to simplicity and ease of feature retrieval, commonly used texture descriptors include co-occurrence texture features, wavelet features and fractal-based texture features.

Table 1. Essential features.

\begin{tabular}{|c|c|c|}
\hline Features & Properties & References \\
\hline \multirow[t]{3}{*}{ Asymmetry } & asymmetry index & $\begin{array}{l}{[27,32,40,57,62,65,130,252,253,291,298,336,344,363,382,387,} \\
388]\end{array}$ \\
\hline & circularity factor & {$[40,51,62,267,291,337,344,349,366,382,386,388$ - 391] } \\
\hline & skewness & {$[103,392]$} \\
\hline \multirow[t]{5}{*}{ Border irregularity } & edge abruptness & {$[57,65,130,252,291,351]$} \\
\hline & lesion areas and perimeters & {$[62,252,253,337,363,366,367,379,382]$} \\
\hline & radial distance & {$[267,369]$} \\
\hline & bounding box & {$[267,344,369,377,382,390]$} \\
\hline & mean and variance of lesion boundary magnitude & {$[40,57,337,344,366,393]$} \\
\hline \multirow[t]{2}{*}{ Border Sharpness } & compactness index & {$[27,57,65,252,337,344,351,379,382,394]$} \\
\hline & fractal dimension & {$[48,57,65,96]$} \\
\hline \multirow[t]{4}{*}{ Colour } & colour homogeneity & {$[51,57,65,252,347,351,363]$} \\
\hline & island of colour & {$[40,51,58,103,130,366,382,391]$} \\
\hline & colour histogram & {$[28,64,198,292,299,345,366,370,376,377,379,382,395-398]$} \\
\hline & RBG statistics (such as ratio, chromaticity, spectral) & {$[57,103,252,253,291,337,344,367,382,385,392,393]$} \\
\hline Diameter & lesion diameter & {$[51,57,168,252,344,369]$} \\
\hline \multirow[t]{5}{*}{$\begin{array}{l}\text { Differential } \\
\text { Structures }\end{array}$} & pigmented network (typical/atypical) & $\begin{array}{l}{[17,21,28,52,58,93,94,121,127,190,242,291,347,358,371,373,} \\
376,399-406]\end{array}$ \\
\hline & homogeneous areas & {$[61,382,407]$} \\
\hline & branched streaks globules & {$[17,52,93,94,345,400,405,406,408]$} \\
\hline & structure-less areas (such as dots, globules, blotches) & $\begin{array}{l}{[17,52,93,94,121,291,345,357,358,376,400,402,405,406,408 \text { - }} \\
410]\end{array}$ \\
\hline & blue-white veil & {$[17,52,58,121,291,372,400,403]$} \\
\hline \multirow{2}{*}{$\begin{array}{l}\text { Lesion Surface } \\
\text { Structures }\end{array}$} & co-occurrence texture features & {$[40,48,51,103,291,344,347,351,366,369,376,382,386,391,392]$} \\
\hline & wavelet texture features & {$[62,64,336,386]$} \\
\hline \multirow[t]{2}{*}{ Other features } & correlation index between geometry and photometry & {$[57,65]$} \\
\hline & sonography characteristics, hypo-echogenicity & {$[57,108,177,411,412]$} \\
\hline
\end{tabular}

Co-occurrence texture descriptors such as entropy, correlation, energy, contrast, homogeneity etc. are based on cooccurrence matrices, typically the GLCM. (Fig. 9) detailed some of the frequently used texture descriptors, as well as corresponding computation. The GLCM [348] also known as greylevel spatial dependence matrix, is a form of statistical method of examining texture in relation to image pixels. GLCM outlines within a grey scale image, the probability of greylevel $i$ occurring at a distance in direction $\theta$ from grey level $\hat{j}$.

$$
C_{\mathrm{i}, \hat{\jmath}}=\operatorname{Pr}(\mathrm{i}, \hat{\jmath} \mid \mathrm{d}, \theta)
$$

Wavelet texture features such as wavelet energy, variance and residual energy are based on wavelet transform coefficients. Fractal based texture features such as mean fractal dimension, local connected fractal dimension and global box-counting are based on fractal dimensions. One major shortfall of local fractal dimensions and local connected fractal dimensions, however, is the dependency on the choice of the maximum window size [48]. However, while it is desirable to determine features to represent these structures directly, extracting these features is often challenging primarily due to a vast variety of dermoscopy images and the highly subjective definitions of these features [40, 41, 96].

A number of different feature selection methods have been used in the literature towards ensuring appropriate 
discriminating features for lesion image classification. Frequent selection methods reported in the literature include Sequential Floating Forward Selection (SFFS) [337], Sequential Floating Backward Selection (SFBS) [337], LeaveOne-Out, Cross Validation (xVal), Plus-I-Take-Away-r, and Genetic algorithm. Zagrouba and Barhoumi [57] argued that relative reduction of selection features could yield 50\% reduction in the processing time, as well as $65 \%$ reduction in the time required to train classifiers.

While these selectors have produced positive results and contribute positively towards classification of lesion images, there resource intensive patterns are still a concern. There is thus a growing need to improve the algorithms implemented by each of the selectors to better achieve optimal feature selection process, which in turn would help reduce complexity and time-consuming computation experienced during quantification of features [349].

\subsection{Classification of Lesion}

Image classification involves using selected features of an image to classify pixels of the image into one of the several classes depending on specific knowledge domain. This could be in the form of training a model using a data set and then testing the model using a data set which is disjoint from the training set. Most lesion classifications are binary in nature, distinguishing between benign and malignant moles. The classification results are typically influenced by the chosen feature descriptors and strength of the classifiers. Performance of the automated classification is equally dependent on the degree of dataset population [168].

The two main classification types as reported in the literature in relation to medical imaging are supervised classification and unsupervised classification. Supervised classification uses image analysis tool to generate a statistical categorisation (such as mean and co-variance) of the reflectance of each identified information class. The completion of the categorisation then fosters effective classification by examining the reflectance of each pixel and deciding on the best matching signatures. Decision criterion such as maximum likelihood can be used for cases of overlapping signatures in order to assign pixels to the highest probable class. Unsupervised classification typically examines a large number of unknown pixels and divides them into a number of classes based on natural groupings present in the image values using procedures such as clustering. Essentially, unsupervised classification groups values that are close together in a measurement space as a single class, thus arranging the data in different classes to be comparatively separated [350].

The literature has reported the application of several classification methods for lesion images. Frequently used among these methods are the Artificial Neural Network (ANN), Decision Trees (DT), K-Nearest Neighbour (KNN), Support Vector Machine (SVM) and Regression Analysis (RA) classifiers. Similar to the neurons of a human brain, ANN comprises of an interconnected group of nodes, otherwise termed as neurons. Neural network models typically consist of both an adaptive weight that is adjusted during model training, as well as the capability to use quantitative characterization to approximate non-linear functions of their inputs.

Popular ANN methods include Back Propagation Network (BPN) [22, 40, 292, 332, 347, 351 - 355], Auto Associative Network (AAN) [22], Multi-Layer Perceptron (MLP) [57, 168, 224, 236, 349, 351, 355 - 357], and Single Layer Perceptron (SLP) [51, 358]. In the literature, extreme Learning Machine (XLM), SLP and MLP seem to be the most commonly used Feed Forward Network (FFN) methods. Main benefits of Bayesian network include its quick training capability and insensitivity to irrelevant features [298]. Sample application of ANN for lesion classification purpose can be seen in different studies [22, 40, 51, 57, 63, 168, 236, 292, 332, 352, 353, 359]. A major challenge in the application of ANN includes the excessive time that might be required in training dataset.

Bayesian network is another frequently used classifier in the space of lesion discrimination [351]. It is a probabilistic graphical model that applies Directed Acyclic Graph (DAG) to represent a set of random variables with their corresponding conditional dependencies. It should be noted that the term Bayesian network depicts the usage of Bayes rule for probabilistic inference and not necessarily implies commitment to Bayesian statistics. One major advantage in the use of Bayesian network is its insensitivity to irrelevant features. Its drawback, however, includes sometimes undesirable assumption declaring that discriminating features are independent [298]. Application and analysis of Bayesian network can be seen in different studies [224, 360 - 364]. In the literature, Hidden Naïve Bayes (HNB) has been observed to perform better than the Bayesian network method used [62, 361]. If a set of lesion outcomes represented by a vector $\mathrm{v}=\mathrm{v} 1, \mathrm{v} 2, \ldots, \mathrm{vn}$ is to be classified to $\mathrm{j}$ possible classes $(\mathrm{Cj})$, then the conditional posterior probability using Bayesian rule can be expressed as: 


$$
p\left(C_{j} \mid v\right)=\frac{p\left(C_{j}\right) p\left(v \mid C_{j}\right)}{p(v)}
$$

Regression analysis is a statistical analysis for estimating the relationship between dependent (criterion) and independent variables (regression function or predictors). This typically tracks changes in the dependent variables as one of the members of the predictors is kept constant while other members of the predictors are varied. Frequently used regression analysis methods include Discriminant Function Analysis (e.g. Linear or Quadratic Regression) [40, 57, 60, 137, 253, 292, 364 - 367] and Logistic Regression [18, 75, 93, 102, 137, 368, 369].

Decision trees typically adopt a tree-like graph of possible decisions and the corresponding outcomes which could trigger another decision till a specific conclusion is reached [291, 361, 369, 370]. The major merit of using decision trees includes the speed at which it can be trained as well as its ease of use. Frequently used DT methods include C4.5 Decision Tree [291, 371 - 373], Logistic Model Tree (LMT) [291, 361, 374], Random Forest [357, 361, 370, 375], and Gradient Boosting (e.g. Adaptive Boosting: AdaBoost) [64, 291, 375 - 380]. Drawbacks seen in the usage of decision trees include difficulties in dealing with correlated features and the likelihood of over-fitting which typically results in excessive adjustments [298]. DT method was dubbed to perform the least in the comparative study described by Dreiseitl et al. [381], however, comparable to human expert.

The K-Nearest Neighbour (K-NN) is an algorithm that can also be applied as a classifier by storing the available cases and then classifying new cases based on the similar measurement in feature space [64, 198, 337, 344, 362]. The classifier input consists of $\mathrm{k}$ closest sample in the feature space, while its output result in class membership of objects being sampled. Contrary to some other classifiers, K-NN does not implement a decision boundary, however, uses the elements of the training set to estimate the density distribution of the data [381]. Hierarchical K-NN is an optimized subset of K-NN, however, it adopts both observation and feature space in its classification procedures.

The SVM is a non-probabilistic binary linear classifier that uses a learning module to analyse patterns within a collection of data for possible classification into one of the two categories. It adopts supervised learning for labelled data and an unsupervised clustering approach when data is not labelled. SVM also provides a unified framework in which different learning machine architectures can further be generated through an appropriate choice of kernel [382]. Applications of SVM can be seen in some studies [42, 130, 291, 354, 363, 369, 383 - 386]. In a number of studies, SVM was judged to outperform several classifiers [354, 357, 360, 363, 375]; and it is often praised for its good generalization and simplification of the non- linear data separation by means of kernel functions [298]. While the application of SVM in discriminating between melanocytic lesions has seen a number of good results, it sometimes could be very sensitive to noise hence producing a poor result. Contrary reports to the effectiveness of SVM when compared to other classifiers has equally been reported by some research works [64, 291]. SVM and MLP performed better than the counterpart classifier in the confusion matrix described in a study [357] between MLP, K-NN, Random Forest (RF) and SVM. In a similar study described by Dreiseitl et al. [381], logistic Regression, ANN and SVM produced good discriminating results for PSL compared to KNN and Decision Tree methods.

Kreutz et al. [336] argued for the need to incorporate a combination of expert systems in classifying lesion images to enable data set to be split into regions where each expert system works effectively. Results from each expert system can then be aggregated by a gating network. This is to help resolve recurrent challenges faced when training a single expert system to classify varying degrees of input space. In effect, when input space is separated and targeted, scalability and interpretability of solutions increase. Similarly, A Multiple Expert-Based Melanoma Recognition System for Dermoscopic Images of Pigmented Skin Lesions has been proposed by Rahman and Bhattacharya [198, 299] by using combination rules generated with the application of Bayes' theorem to produce a probabilistic output. The comparative study discussed by Ruiz et al. [351] equally argued that collaborative classifiers produced better classification compared to the usage of individual classifiers.

Furthermore, Dreiseitl et al. [381] suggested that linear factors contribute to a better discrimination compared to non-linear elements in the classifying models. This was proved in the comparative analysis [381] between K-NN, Logistic Regression, ANN, DT and SVM, where linear method (logistic regression) outperformed non-linear counterpart. Other remarkable classifiers as reported in the literature include Lacunarity analysis [96] and Markov Random Field MRF [246]. The literature also records the use of rule-based process for classifying skin lesion images. Frequently used rule-based procedures include Pattern Analysis, ABCD rule, ELM 7-point checklists, Menzies score, 7 
Features for melanoma. Notable results have been recorded in the literature by various classification methods; however, there still exists some unresolved concerns in relation to effective lesion classification. Highlights of the issues include the great unbalance between lesion image classes, the difficulty in defining discriminating visual features and the effect of multiplicities of some lesion image classes. The execution speeds of the classification algorithms and resource intensive nature of some of these classifiers have posed a need for a more optimized approach, especially when considering mobile portability of these solutions.

\section{CONCLUSION}

The development of automated systems capable of assisting physicians in medical imaging tasks has been seen to be marred by the presence of noise such as masking structures, variability of biological shapes and tissues, and imaging system anisotropy. These noises make an automated analysis of both microscopic and macroscopic images a cumbersome task. We discussed different approaches proposed in the literature for resolving some of the doubts resulting from the automated diagnosis of microscopic (dermoscopic) as well as macroscopic (clinical) images.

Most articles in the literature often assume that malignant moles are pigmented. However, there has been an increase in the reports of non-pigmented skin tumours, as well as clinically and dermoscopic featureless moles being misdiagnosed during both clinical examination and dermoscopy screening, thus necessitating a careful approach.

Among others, subjective opinions resulting from the evaluation of parameters used in lesion segmentation were recorded as one of the difficulties encountered in the literature in an attempt to analyze different automatic border detection methods for lesion images. To achieve a proper measure of accuracy and consistent results when performing lesion localization, we would like to recommend that comparison of segmentation algorithms should be done on the same set of lesion images.

We propose that more efforts should be geared towards optimizing feature selection in order to reduce complexity and time-consuming computation. A number of the classification models proposed in the literature still exhibit some challenges such as unbalance between lesion image classes, the difficulty in defining discriminating visual features and the effect of multiplicities of some lesion image classes. We believe that given a good classification model, less emphasis could be given to the number of features required to discriminate between lesion categories.

\section{CONSENT FOR PUBLICATION}

Not applicable.

\section{CONFLICT OF INTEREST}

The authors declare no conflict of interest, financial or otherwise.

\section{ACKNOWLEDGEMENTS}

Declared none.

\section{REFERENCES}

[1] Tushabe F, Mwebaze E, Kiwanuka FN. An image-based diagnosis of virus and bacterial skin infections The International Congress on Complications in Interventional Radiology (ICCIR).

[2] World Health Organization. (2007, Jan 5, 2012). Report: Essential Health technologies Strategy 2004-2007 Available from: http://www.who.int/eht/en/EHT_strategy_2004-2007.pdf

[3] Gençler B, Gönül M. Cutaneous side effects of BRAF inhibitors in advanced melanoma: Review of literatures. Dermatol Res Pract 2016; Vol. 2016 .

[4] Tsao H, Bevona C, Goggins W, Quinn T. The transformation rate of moles (melanocytic nevi) into cutaneous melanoma: A population-based estimate. Arch Dermatol 2003; 139(3): 282-8.

[http://dx.doi.org/10.1001/archderm.139.3.282] [PMID: 12622618]

[5] Friedman RJ, Farber MJ, Warycha MA, Papathasis N, Miller MK, Heilman ER. The “dysplastic" nevus. Clin Dermatol 2009; $27(1)$ : 103-15. [http://dx.doi.org/10.1016/j.clindermatol.2008.09.008] [PMID: 19095156]

[6] Grant-Kels JM, Bason ET, Grin CM. The misdiagnosis of malignant melanoma. J Am Acad Dermatol 1999; 40(4): 539-48. [http://dx.doi.org/10.1016/S0190-9622(99)70435-4] [PMID: 10188671]

[7] Stratigos AJ, Katsambas AD. The value of screening in melanoma. Clin Dermatol 2009; 27(1): 10-25. [http://dx.doi.org/10.1016/j.clindermatol.2008.09.002] [PMID: 19095150] 
[8] Botella-Estrada R, Sanmartín O, Sevila A, Escudero A, Guillén C. Melanotic pigmentation in excision scars of melanocytic and nonmelanocytic skin tumors. J Cutan Pathol 1999; 26(3): 137-44. [http://dx.doi.org/10.1111/j.1600-0560.1999.tb01818.x] [PMID: 10235379]

[9] Laishram RS, Myrthong BG, Laishram S, Shimray R. A. K. K, and D. C. Sharma, "Pigmented skin lesions: Are they all of melanocytic origin? A histopathological perspective. J Pak Assoc Dermatol 2013; 23: 284-8.

[10] Sam AH, Teo JTH. Rapid Medicine. Wiley-Blackwell 2010.

[11] Friedman RJ, Rigel DS, Kopf AW. Early detection of malignant melanoma: The role of physician examination and self-examination of the skin. CA Cancer J Clin 1985; 35(3): 130-51. [http://dx.doi.org/10.3322/canjclin.35.3.130] [PMID: 3921200]

[12] Fitzpatrick TB, Rhodes AR, Sober AJ, Mihm MC. Primary malignant melanoma of the skin: The call for action to identify persons at risk, to discover precursor lesion, to detect early melanoma. Pigment Cell Res 1988; 9: 110-7.

[13] MacKie RM. Clinical recognition of early invasive malignant melanoma. BMJ 1990; 301(6759): $1005-6$. [http://dx.doi.org/10.1136/bmj.301.6759.1005] [PMID: 2249043]

[14] Stolz W, Riemann A, Cognetta A. ABCD rule of dermoscopy: A new practical method for early recognition of malignant melanoma. Eur J Dermatol 1994; 4: 521-7.

[15] Healsmith MF, Bourke JF, Osborne JE, Graham-Brown RA. An evaluation of the revised seven-point checklist for the early diagnosis of cutaneous malignant melanoma. Br J Dermatol 1994; 130(1): 48-50. [http://dx.doi.org/10.1111/j.1365-2133.1994.tb06881.x] [PMID: 8305316]

[16] Hazen BP, Bhatia AC, Zaim T, Brodell RT. The clinical diagnosis of early malignant melanoma: Expansion of the ABCD criteria to improve diagnostic sensitivity. Dermatol Online J 1999; 5(2): 3.

[PMID: 10673456]

[17] Argenziano G, Soyer HP. Dermoscopy of pigmented skin lesions-A valuable tool for early diagnosis of melanoma. Lancet Oncol 2001; 2(7): 443-9. [http://dx.doi.org/10.1016/S1470-2045(00)00422-8] [PMID: 11905739]

[18] Lucas C R, Sanders L L, Murray J C, Myers S A, Hall R P, Grichnik J M. Early melanoma detection: Nonuniform dermoscopic features and growth J Dermatol 2003; 48 [http://dx.doi.org/10.1067/mjd.2003.283]

[19] Abbasi NR, Shaw HM, Rigel DS, et al. Early diagnosis of cutaneous melanoma: Revisiting the ABCD criteria. JAMA 2004; 292 (22): 2771-6. [http://dx.doi.org/10.1001/jama.292.22.2771] [PMID: 15585738]

[20] Zouridakis G, Doshi M, Mullani N. Early diagnosis of skin cancer based on segmentation and measurement of vascularization and pigmentation in Nevoscope images. Conf Proc IEEE Eng Med Biol Soc 2004; 3: 1593-6. [EMBS]. [PMID: 17272004]

[21] Geller AC, Swetter SM, Brooks K, Demierre M-F, Yaroch AL. Screening, early detection, and trends for melanoma: Current status (2000-2006) and future directions. J Am Acad Dermatol 2007; 57(4): 555-72. [http://dx.doi.org/10.1016/j.jaad.2007.06.032] [PMID: 17870429]

[22] Lau HT, Al-Jumaily A. Automatically early detection of skin cancer: Study based on neural netwok classification Inter Conf Soft Comp Pattern Reco. 375-80. [http://dx.doi.org/10.1109/SoCPaR.2009.80]

[23] Hoshyar AN, Sulaiman AA-JR. Review on automatic early skin cancer detection International Conference on Computer Science and Service System (CSSS). Nanjing. 2011.

[http://dx.doi.org/10.1109/CSSS.2011.5974581]

[24] Do T-T, Zhou Y, Zheng H, Cheung N-M. Early melanoma diagnosis with mobile imaging 36th IEEE annual international conference of the engineering in medicine and biology society (EMBC).

[25] Perakis K, Bouras T, Kostopoulous S, Sidiropoulos K. MARK1 - A decision support system for the early detection of malignant melanoma 4th EAI International Conference on Wireless Mobile Communication and Healthcare (Mobihealth). Athens. 2014. [http://dx.doi.org/10.4108/icst.mobihealth.2014.257247]

[26] Tsao H, Olazagasti JM, Cordoro KM, et al. Early detection of melanoma: Reviewing the ABCDEs. J Am Acad Dermatol 2015; 72(4): 717-23. [http://dx.doi.org/10.1016/j.jaad.2015.01.025] [PMID: 25698455]

[27] Hadi S, Tumbelaka BY, Irawan B, Rosadi R. Implementing DEWA framework for early diagnosis of melanoma. Procedia Comput Sci 2015; 59: $410-8$

[http://dx.doi.org/10.1016/j.procs.2015.07.555]

[28] Abuzaghleh O, Barkana BD, Faezipour M. Noninvasive Real-Time automated skin lesion analysis system for melanoma early detection and prevention. IEEE J Transl Eng Health Med 2015; 3: 2900310. [http://dx.doi.org/10.1109/JTEHM.2015.2419612] [PMID: 27170906]

[29] Ali A-RA, Deserno TM. A systematic review of automated melanoma detection in dermatoscopic images and its ground truth data.Society of 
Photo-Optical Instrumentation Engineers. SPIE 2012. [http://dx.doi.org/10.1117/12.912389]

[30] Han J, Colditz G A, Hunter D J. Risk factors for skin cancer: A nested case-control study within the Nurse's health study Int J Epidemiol $2006 ; 35$ [http://dx.doi.org/10.1093/ije/dyl197]

[31] Sboner A, Blanzieri E, Eccher C, Baurer P, Cristofolini M, Zumiani G, et al. A knowledge based system for early melanoma diagnosis support, 6th IDAMAP Workshop - Intelligent Data Analysis in Medicine and Pharmacology. London, UK. 2001.

[32] Schmid-Saugeona P, Guillodb J, Thirana JP. Towards a computer-aided diagnosis system for pigmented skin lesions. Comput Med Imaging Graph 2003; 27(1): 65-78. [http://dx.doi.org/10.1016/S0895-6111(02)00048-4] [PMID: 12573891]

[33] Australian Institute of Health and Welfare \& Australian Association of Cancer Registries. Cancer in Australia In: 2012.

[34] Robinson JK. Sun exposure, sun protection, and vitamin D. JAMA 2005; 294(12): 1541-3. [http://dx.doi.org/10.1001/jama.294.12.1541] [PMID: 16193624]

[35] National Cancer Institute.(2012, Dec 12, 2013). Sun Protection Cancer Trends Progress Report 2011-2012 Update Available from: http://progressreport.cancer.gov/doc_detail.asp?pid=1\&did=2007\&chid=71\&coid=711\&mid

[36] American Cancer Society. (2016, Feb 24, 2016). Cancer Facts and Figures Available from: http://www.cancer.org/acs/groups/content/@research/documents/document/acspc-047079.pdf

[37] Bleyer AA, O’Leary MC, Barr RD, Ries LAG. Cancer Epidemiology in Older Adolescents and Young Adults 15 to 29 Years of Age, Including SEER Incidence and Survival: 1975-2000 In: 2006.

[38] American Cancer Society. (2015, Nov 13, 2015). http://www.cancer.org/acs/groups/ content/@editorial/ documents/document/acspc-044552.pdf

[39] American Cancer Society. (2017, Sep 09, 2017). Cancer Facts \& Figures. Available: https://www.cancer.org/content/dam/cancer-org/ research/cancer-facts-and-statistics/annual-cancer-facts-and-figures/ 2017/cancer-facts-and-figures-2017.pdf

[40] Iyatomi H, Oka H, Celebi ME, et al. An improved Internet-based melanoma screening system with dermatologist-like tumor area extraction algorithm. Comput Med Imaging Graph 2008; 32(7): 566-79. [http://dx.doi.org/10.1016/j.compmedimag.2008.06.005] [PMID: 18703311]

[41] Iyatomi H, Oka H, Saito M, et al. Quantitative assessment of tumour extraction from dermoscopy images and evaluation of computer-based extraction methods for an automatic melanoma diagnostic system. Melanoma Res 2006; 16(2): 183-90. [http://dx.doi.org/10.1097/01.cmr.0000215041.76553.58] [PMID: 16567974]

[42] Stanganelli I, Brucale A, Calori L, Gori R, Lovato A, Magi S, et al. Computer-aided diagnosis of melanocytic lesions in Anticancer Res. 2005; pp. 4577-82.

[43] Asuquo ME, Nwagbara VI, Otel OO, Bassey I, Ugbem T. Cutaneous Malignant Melanoma in Calabar, South Nigeria. University of Calabar Teaching Hospital 2012.

[44] Samalia MOA, Rafindadi AH. Pattern of Cutaneous malignant melanoma in Zaria, Nigeria. Ann Afr Med 2006; 5: 16-9.

[45] Tuma B, Yamada S, Atallah AN, Araujo FM, Hirata SH. Dermoscopy of black skin: A cross-sectional study of clinical and dermoscopic features of melanocytic lesions in individuals with type V/VI skin compared to those with type I/II skin. J Am Acad Dermatol 2015; 73(1): 114-9. [http://dx.doi.org/10.1016/j.jaad.2015.03.043] [PMID: 25982540]

[46] Jemal A, Siegel R, Xu J, Ward E. Cancer statistics, 2010. CA Cancer J Clin 2010; 60(5): 277-300. [http://dx.doi.org/10.3322/caac.20073] [PMID: 20610543]

[47] Cancer Association Of South Africa (CANSA). (2010, May 22, 2013). http://www.cansa.org.za/files/ 2012/05/SKIN_CANCER_ leaflet-2010.pdf

[48] Dobrescu R, Dobrescu M, Mocanu S, Popescu D. Medical images classification for skin cancer diagnosis based on combined texture and fractal analysis. In: World Scientific and Engineering Academy and Society. WSEAS Transactions on Biology and Biomedicine 2010.

[49] Kantrowitz M. (2009, Jan 16, 2014). Pathology Reports May Contain Errors. Available: http://www.kantrowitz.com/ cancerpoints/ diagnosiserrors.html

[50] Singh H, Sethi S, Raber M, Petersen L A. Errors in cancer diagnosis: Current understanding and future directions J Clin Oncol 2007; 5009-18. [http://dx.doi.org/10.1200/JCO.2007.13.2142]

[51] Rubegni P, Cevenini G, Burroni M, et al. Automated diagnosis of pigmented skin lesions. Int J Cancer 2002; 101(6): 576-80. [http://dx.doi.org/10.1002/ijc.10620] [PMID: 12237900]

[52] Argenziano G, Soyer HP, Chimenti S, et al. Dermoscopy of pigmented skin lesions: results of a consensus meeting via the Internet. J Am Acad Dermatol 2003; 48(5): 679-93. [http://dx.doi.org/10.1067/mjd.2003.281] [PMID: 12734496]

[53] Rosendahl C, Tschandl P, Cameron A, Kittler H. Diagnostic accuracy of dermatoscopy for melanocytic and nonmelanocytic pigmented lesions. J Am Acad Dermatol 2011; 64(6): 1068-73. 
[http://dx.doi.org/10.1016/j.jaad.2010.03.039] [PMID: 21440329]

[54] Laws KI. Textured image segmentation. DTIC Document 1980. [http://dx.doi.org/10.21236/ADA083283]

[55] Abbas Q, Celebi ME, García IF. Hair removal methods: A comparative study for dermoscopy images. Biomed Signal Process Control 2011; 6: 395-404. [http://dx.doi.org/10.1016/j.bspc.2011.01.003]

[56] Kittler H. Dermoscopy of pigmented skin lesions. G Ital Dermatol Venereol 2004; 139: 541-6.

[57] Zagrouba E, Barhoumi W. An accelerated system for melanoma diagnosis based on subset feature selection. Int J Comput Models Algorithms Med 2005; 13: 69-82.

[58] Benvenuto-Andrade C, Dusza SW, Agero ALC, et al. Differences between polarized light dermoscopy and immersion contact dermoscopy for the evaluation of skin lesions. Arch Dermatol 2007; 143(3): 329-38. [http://dx.doi.org/10.1001/archderm.143.3.329] [PMID: 17372097]

[59] Argenziano G, Soyer HP, Chimenti S, Argenziano G, Ruocco V. Impact of dermoscopy on the clinical management of pigmented skin lesions. Clin Dermatol 2002; 20(3): 200-2. [http://dx.doi.org/10.1016/S0738-081X(02)00234-1] [PMID: 12074853]

[60] Zortea M, Schopf TR, Thon K, et al. Performance of a dermoscopy-based computer vision system for the diagnosis of pigmented skin lesions compared with visual evaluation by experienced dermatologists. Artif Intell Med 2014; 60(1): 13-26. [http://dx.doi.org/10.1016/j.artmed.2013.11.006] [PMID: 24382424]

[61] Malvehy J, Puig S, Argenziano G, Marghoob AA, Soyer HP. Dermoscopy report: Proposal for standardization. Results of a consensus meeting of the International Dermoscopy Society. J Am Acad Dermatol 2007; 57(1): 84-95. [http://dx.doi.org/10.1016/j.jaad.2006.02.051] [PMID: 17482314]

[62] Garnavi R, Aldeen M, Bailey J. Computer-Aided diagnosis of melanoma using border- and wavelet-based texture analysis. 2012.

[63] Mittra AK, Parekh R. Automated detection of skin disease using texture features. Int J Eng Sci Technol 2011 ; 3(June): 2011.

[64] Barata C, Ruela M, Francisco M, Mendonça T, Marques JS. Two systems for the detection of melanomas in dermoscopy images using texture and color features. IEEE Syst J 2013.

[65] Zagrouba E, Barhoumi W. A preliminary approach for the automated recognition of malignant melanoma. Image Anal Stereol 2004; 23: 121-35.

[http://dx.doi.org/10.5566/ias.v23.p121-135]

[66] Blum A, Rassner G, Garbe C. Modified ABC-point list of dermoscopy: A simplified and highly accurate dermoscopic algorithm for the diagnosis of cutaneous melanocytic lesions. J Am Acad Dermatol 2003; 48(5): 672-8. [http://dx.doi.org/10.1067/mjd.2003.282] [PMID: 12734495]

[67] Pehamberger H, Steiner A, Wolff K. In vivo epiluminescence microscopy of pigmented skin lesions. I. Pattern analysis of pigmented skin lesions. J Am Acad Dermatol 1987; 17(4): 571-83. [http://dx.doi.org/10.1016/S0190-9622(87)70239-4] [PMID: 3668002]

[68] Menzies SW, Ingvar C, Crotty KA, McCarthy WH. Frequency and morphologic characteristics of invasive melanomas lacking specific surface microscopic features. Arch Dermatol 1996; 132(10): 1178-82. [http://dx.doi.org/10.1001/archderm.1996.03890340038007] [PMID: 8859028]

[69] Mackie RM, Doherty VR. Seven-point checklist for melanoma. Clin Exp Dermatol 1991; 16(2): 151-3. [http://dx.doi.org/10.1111/j.1365-2230.1991.tb00329.x] [PMID: 1867692]

[70] Argenziano G, Fabbrocini G, Carli P, De Giorgi V, Sammarco E, Delfino M. Epiluminescence microscopy for the diagnosis of doubtful melanocytic skin lesions. Comparison of the ABCD rule of dermatoscopy and a new 7-point checklist based on pattern analysis. Arch Dermatol 1998; 134(12): 1563-70.

[http://dx.doi.org/10.1001/archderm.134.12.1563] [PMID: 9875194]

[71] Dal Pozzo V, Benelli C, Roscetti E. The seven features for melanoma: A new dermoscopic algorithm for the diagnosis of malignant melanoma. Eur J Dermatol 1999; 9(4): 303-8. [PMID: 10356410]

[72] Henning JS, Dusza SW, Wang SQ, et al. The CASH (color, architecture, symmetry, and homogeneity) algorithm for dermoscopy. J Am Acad Dermatol 2007; 56(1): 45-52. [http://dx.doi.org/10.1016/j.jaad.2006.09.003] [PMID: 17190620]

[73] Henning JS, Stein JA, Yeung J, et al. CASH algorithm for dermoscopy revisited. Arch Dermatol 2008; 144(4): 554-5. [http://dx.doi.org/10.1001/archderm.144.4.554] [PMID: 18427058]

[74] Meo N D, Stinco G, Bonin S, Gatti A, Trevisini S, Damiani G, et al. CASH algorithm versus 3-point checklist and its modified version in evaluation of melanocytic pigmented skin lesions: The 4-point checklist J Dermatol 2015; 42

[75] Haenssle H A, Korpas B, Hansen-Hagge C, Buhl T, Kaune K M, Rosenberger A, et al. Seven-point checklist for dermatoscopy: Performance during 10 years of prospective surveillance of patients at increased melanoma risk J Am Acad Dermaatol Mar 12, 20102009. 
[76] Walter FM, Prevost AT, Vasconcelos J, et al. Using the 7-point checklist as a diagnostic aid for pigmented skin lesions in general practice: A diagnostic validation study. Br J Gen Pract 2013; 63(610): e345-53. [http://dx.doi.org/10.3399/bjgp13X667213] [PMID: 23643233]

[77] Andersen WK, Silvers DN. 'Melanoma? It can’t be melanoma!' A subset of melanomas that defies clinical recognition. JAMA 1991; 266(24): 3463-5. [http://dx.doi.org/10.1001/jama.1991.03470240085038] [PMID: 1744961]

[78] Bergman R, Katz I, Lichtig C, Ben-Arieh Y, Moscona AR, Friedman-Birnbaum R. Malignant melanomas with histologic diameters less than 6 mm. J Am Acad Dermatol 1992; 26(3 Pt 2): 462-6 [http://dx.doi.org/10.1016/0190-9622(92)70073-O] [PMID: 1564154]

[79] Braun-Falco M, Hein R, Ring J, McNutt NS. Histopathological characteristics of small diameter melanocytic naevi. J Clin Pathol 2003; 56(6): 459-64. [http://dx.doi.org/10.1136/jcp.56.6.459] [PMID: 12783974]

[80] Marghoob AA, Scope A. The complexity of diagnosing melanoma. J Invest Dermatol 2009; 129(1): 11-3. [http://dx.doi.org/10.1038/jid.2008.388] [PMID: 19078984]

[81] Paul SP. Micromelanomas: A review of melanomas $\leq 2 \mathrm{~mm}$ and a case report. Case Rep Oncol Med 2014; $2014: 206260$. [http://dx.doi.org/10.1155/2014/206260] [PMID: 24716040]

[82] Goldsmith SM, Solomon AR. A series of melanomas smaller than $4 \mathrm{~mm}$ and implications for the ABCDE rule. J Eur Acad Dermatol Venereol 2007; 21(7): 929-34. [http://dx.doi.org/10.1111/j.1468-3083.2006.02115.x] [PMID: 17659002]

[83] Whiteman DC, Baade PD, Olsen CM. More people die from thin melanomas ( $\square 1 \mathrm{~mm})$ than from thick melanomas ( $>4 \mathrm{~mm})$ in Queensland, Australia. J Invest Dermatol 2015; 135(4): 1190-3. [http://dx.doi.org/10.1038/jid.2014.452] [PMID: 25330295]

[84] Zaharna M, Brodell RT. It's time for a change in Our approach to early detection of malignant melanoma. In: Clin Dermatol. 2003 ; Vol. 21.

[85] Liu W, Hill D, Gibbs AF, et al. What features do patients notice that help to distinguish between benign pigmented lesions and melanomas?: the $\mathrm{ABCD}(\mathrm{E})$ rule versus the seven-point checklist. Melanoma Res 2005; 15(6): 549-54. [http://dx.doi.org/10.1097/00008390-200512000-00011] [PMID: 16314742]

[86] Rigel DS, Friedman RJ. The rationale of the ABCDs of early melanoma. J Am Acad Dermatol 1993; 29(6): 1060-1. [http://dx.doi.org/10.1016/S0190-9622(08)82059-2] [PMID: 8245255]

[87] Thomas L, Tranchand P, Berard F, Secchi T, Colin C, Moulin G. Semiological value of ABCDE criteria in the diagnosis of cutaneous pigmented tumors. Dermatology (Basel) 1998; 197(1): 11-7. [http://dx.doi.org/10.1159/000017969] [PMID: 9693179]

[88] Grob JJ, Bonerandi JJ. The 'ugly duckling' sign: identification of the common characteristics of nevi in an individual as a basis for melanoma screening. Arch Dermatol 1998; 134(1): 103-4. [http://dx.doi.org/10.1001/archderm.134.1.103-a] [PMID: 9449921]

[89] Grob JJ, Wazaefi Y, Bruneu Y, Gaudy-Marqueste C, Monestier S, Thomas L, et al. Diagnosis of melanoma: Importance of comparative analysis and ugly duckling sign. J Clin Oncol 2012; 30: 8578.

[90] Daniel Jensen J, Elewski BE. The ABCDEF Rule: Combining the "ABCDE Rule" and the "Ugly Duckling Sign" in an effort to improve patient self-screening examinations. J Clin Aesthet Dermatol 2015; 8(2): 15. [PMID: 25741397]

[91] Weinstock MA. ABCD, ABCDE, and ABCCCDEEEEFNU. Arch Dermatol 2006; 142(4): 528. [http://dx.doi.org/10.1001/archderm.142.4.528-a] [PMID: 16618883]

[92] Lallas A, Kyrgidis A, Koga H, et al. The BRAAFF checklist: a new dermoscopic algorithm for diagnosing acral melanoma. Br J Dermatol 2015; 173(4): 1041-9. [http://dx.doi.org/10.1111/bjd.14045] [PMID: 26211689]

[93] Annessi G, Bono R, Sampogna F, Faraggiana T, Abeni D. Sensitivity, specificity, and diagnostic accuracy of three dermoscopic algorithmic methods in the diagnosis of doubtful melanocytic lesions: the importance of light brown structureless areas in differentiating atypical melanocytic nevi from thin melanomas. J Am Acad Dermatol 2007; 56(5): 759-67. [http://dx.doi.org/10.1016/j.jaad.2007.01.014] [PMID: 17316894]

[94] Dolianitis C, Kelly J, Wolfe R, Simpson P. Comparative performance of 4 dermoscopic algorithms by nonexperts for the diagnosis of melanocytic lesions. Arch Dermatol 2005; 141(8): 1008-14. [http://dx.doi.org/10.1001/archderm.141.8.1008] [PMID: 16103330]

[95] Day GR, Barbour RH. Automated melanoma diagnosis: where are we at? Skin Res Technol 2000; 6(1): 1-5. [http://dx.doi.org/10.1034/j.1600-0846.2000.006001001.x] [PMID: 11428935]

[96] Gilmore S, Hofmann-Wellenhof R, Muir J, Soyer HP. Lacunarity analysis: A promising method for the automated assessment of melanocytic naevi and melanoma. PLoS One 2009; 4(10): e7449. [http://dx.doi.org/10.1371/journal.pone.0007449] [PMID: 19823688] 
[97] Detrixhe A, Libon F, Mansuy M, et al. Melanoma masquerading as nonmelanocytic lesions. Melanoma Res 2016; 26(6): 631-4. [http://dx.doi.org/10.1097/CMR.0000000000000294] [PMID: 27537773]

[98] Tashiro J, Perlyn CA, Melnick SJ, Gulec SA, Burnweit CA. Non-pigmented melanoma with nodal metastases masquerading as pyogenic granuloma in a 1-year old. J Pediatr Surg 2014; 49(4): 653-5. [http://dx.doi.org/10.1016/j.jpedsurg.2014.01.007] [PMID: 24726130]

[99] Diniz G, Tosun Yildirim H, Yamaci S, Olgun N. Nonpigmented metastatic melanoma in a two-year-old girl: A serious diagnostic dilemma. Case Rep Oncol Med 2015; 2015: 298273. [http://dx.doi.org/10.1155/2015/298273] [PMID: 25763285]

[100] Zalaudek I, Kreusch J, Giacomel J, Ferrara G, Catricala C, Argenziano G. How to diagnose nonpigmented skin tumors: a review of vascular structures seen with dermoscopy: part I Melanocytic skin tumors. J Am Acad Dermaatol 2010; Vol. 63: pp. 361-74.

[101] Carli P, Massi D, de Giorgi V, Giannotti B. Clinically and dermoscopically featureless melanoma: When prevention fails. J Am Acad Dermatol 2002; 46(6): 957-9. [http://dx.doi.org/10.1067/mjd.2002.120569] [PMID: 12063500]

[102] Blum A, Luedtke H, Ellwanger U, Schwabe R, Rassner G, Garbe C. Digital image analysis for diagnosis of cutaneous melanoma. Development of a highly effective computer algorithm based on analysis of 837 melanocytic lesions. Br J Dermatol 2004; 151(5): 1029-38. [http://dx.doi.org/10.1111/j.1365-2133.2004.06210.x] [PMID: 15541081]

[103] Iyatomi H, Norton K, Celebi ME, Schaefer G, Tanaka M, Ogawa K. Classification of melanocytic skin lesions from non-melanocytic lesions 32nd Annual International Conference of the IEEE Engineering in Medicine and Biology Society (EMBS). Buenos Aires, Argentina. 2010. [http://dx.doi.org/10.1109/IEMBS.2010.5626500]

[104] Schindewolf T, Schiffner R, Stolz W, Albert R, Abmayr W, Harms H. Evaluation of different image acquisition techniques for a computer vision system in the diagnosis of malignant melanoma. J Am Acad Dermatol 1994; 31(1): 33-41. [http://dx.doi.org/10.1016/S0190-9622(94)70132-6] [PMID: 8021369]

[105] Green A, Martin N, Pfitzner J, O’Rourke M, Knight N. Computer image analysis in the diagnosis of melanoma. J Am Acad Dermatol 1994; 31(6): 958-64. [http://dx.doi.org/10.1016/S0190-9622(94)70264-0] [PMID: 7962777]

[106] Cascinelli N, Ferrario M, Tonelli T, Leo E. A possible new tool for clinical diagnosis of melanoma: the computer. J Am Acad Dermatol 1987; 16(2 Pt 1): 361-7. [http://dx.doi.org/10.1016/S0190-9622(87)70050-4] [PMID: 3819073]

[107] Huang A, Kwan S-Y, Chang W-Y, Liu M-Y, Chi M-H, Chen G-S. A Robust Hair Segmentation and Removal Approach for Clinical Images of Skin Lesions $35^{\text {th }}$ Annual International Conference of the IEEE Engineering in Medicine and Biology Society (EMBC). 3315-8. [http://dx.doi.org/10.1109/EMBC.2013.6610250]

[108] Marghoob AA, Swindle LD, Moricz CZM, et al. Instruments and new technologies for the in vivo diagnosis of melanoma. J Am Acad Dermatol 2003; 49(5): 777-97. [http://dx.doi.org/10.1016/S0190-9622(03)02470-8] [PMID: 14576657]

[109] Menge TD, Pellacani G. Advances in noninvasive imaging of melanoma. Semin Cutan Med Surg 2016; 35(1): 18-24. [http://dx.doi.org/10.12788/j.sder.2016.003] [PMID: 26963113]

[110] Dancey AL, Mahon BS, Rayatt SS. A review of diagnostic imaging in melanoma. J Plast Reconstr Aesthet Surg 2008; 61(11): 1275-83. [http://dx.doi.org/10.1016/j.bjps.2008.04.034] [PMID: 18694659]

[111] Forsea AM, Tschandl P, Del Marmol V, et al. Factors driving the use of dermoscopy in Europe: A pan-European survey. Br J Dermatol 2016; 175(6): 1329-37. [http://dx.doi.org/10.1111/bjd.14895] [PMID: 27469990]

[112] Moscarella E, Tion I, Zalaudek I, Lallas A, Kyrgidis A, Longo C, et al. Both short-term and long-term dermoscopy monitoring is useful in detecting melanoma in patients with multiple atypical nevi. J Eur Acad Dermatol Venereol 2016. [PMID: 27422807]

[113] Noor O II, Nanda A, Rao BK. A dermoscopy survey to assess who is using it and why it is or is not being used. Int J Dermatol 2009; 48(9): 951-2. [http://dx.doi.org/10.1111/j.1365-4632.2009.04095.x] [PMID: 19702978]

[114] Braun RP, Saurat JH, French LE. Dermoscopy of pigmented lesions: A valuable tool in the diagnosis of melanoma. Swiss Med Wkly 2004; 134(7-8): 83-90. [PMID: 15106024]

[115] Ribero S, Marra E, Tomasini CF, Fierro MT, Bombonato C, Longo C. Confocal microscopy and dermoscopy for the monitoring of BRAF inhibitor therapy of melanoma skin metastases. Br J Dermatol 2016. [PMID: 27515562]

[116] Kittler H, Pehamberger H, Wolff K, Binder M. Diagnostic accuracy of dermoscopy. Lancet Oncol 2002; 3(3): 159-65. [http://dx.doi.org/10.1016/S1470-2045(02)00679-4] [PMID: 11902502]

[117] Stolz W, Semmelmayer U, Johow K, Burgdorf WH. Principles of dermatoscopy of pigmented skin lesions. Semin Cutan Med Surg 2003; 22(1): 9-20. 
[http://dx.doi.org/10.1053/sder.2003.50001] [PMID: 12773010]

[118] Lallas A, Apalla Z, Lazaridou E, Ioannides D. Chapter 3 - Dermoscopy In: Imaging in Dermatology, P Avci and G K Gupta, Eds, ed Boston: Academic Press. 2016; pp. 13-28.

[119] Bafounta ML, Beauchet A, Aegerter P, Saiag P. Is dermoscopy (epiluminescence microscopy) useful for the diagnosis of melanoma? Results of a meta-analysis using techniques adapted to the evaluation of diagnostic tests. Arch Dermatol 2001; 137(10): 1343-50. [http://dx.doi.org/10.1001/archderm.137.10.1343] [PMID: 11594860]

[120] Tromme I, Legrand C, Devleesschauwer B, et al. Cost-effectiveness analysis in melanoma detection: A transition model applied to dermoscopy. Eur J Cancer 2016; 67: 38-45.

[http://dx.doi.org/10.1016/j.ejca.2016.07.020] [PMID: 27592070]

[121] Crotty KA, Menzies SW. Dermoscopy and its role in diagnosing melanocytic lesions: A guide for pathologists. Pathology 2004; 36(5): 470-7. [http://dx.doi.org/10.1080/00313020412331283851] [PMID: 15370118]

[122] De Giorgi V, Carli P. Dermoscopy and preoperative evaluation of melanoma thickness. Clin Dermatol 2002; 20(3): 305-8. [http://dx.doi.org/10.1016/S0738-081X(02)00224-9] [PMID: 12074872]

[123] Ciudad-Blanco C, Avilés-Izquierdo JA, Lázaro-Ochaita P, Suárez-Fernández R. Dermoscopic findings for the early detection of melanoma: an analysis of 200 cases. Actas Dermosifiliogr 2014; 105(7): 683-93. [http://dx.doi.org/10.1016/j.adengl.2014.07.015] [PMID: 24704190]

[124] Ferrari A, Peris K, Piccolo D, Chimenti S. Dermoscopic features of cutaneous local recurrent melanoma. J Am Acad Dermatol 2000; 43(4): $722-4$. [http://dx.doi.org/10.1067/mjd.2000.107942] [PMID: 11004641]

[125] de Giorgi V, Sestini S, Massi D, Maio V, Giannotti B. Dermoscopy for "true" amelanotic melanoma: A clinical dermoscopic-pathologic case study. J Am Acad Dermatol 2006; 54(2): 341-4. [http://dx.doi.org/10.1016/j.jaad.2005.04.040] [PMID: 16443072]

[126] Braun RP, Marghoob A. High-dynamic-range dermoscopy imaging and diagnosis of hypopigmented skin cancers. JAMA Dermatol 2015; 151(4): 456-7.

[http://dx.doi.org/10.1001/jamadermatol.2014.4714] [PMID: 25535875]

[127] Braun RP, Oliviero M, Kolm I, French LE, Marghoob AA, Rabinovitz H. Dermoscopy: what's new? Clin Dermatol 2009; $27(1)$ : 26-34. [http://dx.doi.org/10.1016/j.clindermatol.2008.09.003] [PMID: 19095151]

[128] Chappuis P, Duru G, Marchal O, Girier P, Dalle S, Thomas L. Dermoscopy, a useful tool for general practitioners in melanoma screening: a nationwide survey. Br J Dermatol 2016; 175(4): 744-50. [http://dx.doi.org/10.1111/bjd.14495] [PMID: 26914613]

[129] Johr RH. Dermoscopy: alternative melanocytic algorithms-the ABCD rule of dermatoscopy, Menzies scoring method, and 7-point checklist. Clin Dermatol 2002; 20(3): 240-7. [http://dx.doi.org/10.1016/S0738-081X(02)00236-5] [PMID: 12074859]

[130] Mete M, Sirakov NM. Dermoscopic diagnosis of melanoma in a 4D space constructed by active contour extracted features. Comput Med Imaging Graph 2012; 36(7): 572-9.

[http://dx.doi.org/10.1016/j.compmedimag.2012.06.002] [PMID: 22819294]

[131] Taylor S, Westerhof W, Im S, Lim J. Noninvasive techniques for the evaluation of skin color. J Am Acad Dermatol 2006; 54(5)(Suppl. 2): S282-90. [http://dx.doi.org/10.1016/j.jaad.2005.12.041] [PMID: 16631969]

[132] Menzies SW. Cutaneous melanoma: Making a clinical diagnosis, present and future. Dermatol Ther 2006; 19(1): 32-9. [http://dx.doi.org/10.1111/j.1529-8019.2005.00054.x] [PMID: 16405568]

[133] Psaty EL, Halpern AC. Current and emerging technologies in melanoma diagnosis: The state of the art. Clin Dermatol 2009; $27(1): 35-45$. [http://dx.doi.org/10.1016/j.clindermatol.2008.09.004] [PMID: 19095152]

[134] Silveira CEG, Silva TB, Fregnani JHGT, Vieira RAC, Haikel RL, Syrjänen K, et al. Digital photography in skin cancer screening by mobile units in remote areas of Brazil. BMC Dermatol 2014; Vol. 14.

[135] Yancovitz M, Finelt N, Warycha MA, et al. Role of radiologic imaging at the time of initial diagnosis of stage T1b-T3b melanoma. Cancer 2007; 110(5): 1107-14. [http://dx.doi.org/10.1002/cncr.22868] [PMID: 17620286]

[136] Gamo R, Pampín A, Floristán U. Reflectance confocal microscopy in lentigo maligna. Actas dermo-sifiliográficas 2016; Vol. S0001-7310.

[137] Pellacani G, Guitera P, Longo C, Avramidis M, Seidenari S, Menzies S. The impact of in vivo reflectance confocal microscopy for the diagnostic accuracy of melanoma and equivocal melanocytic lesions. J Invest Dermatol 2007; 127(12): 2759-65. [http://dx.doi.org/10.1038/sj.jid.5700993] [PMID: 17657243]

[138] Lorber A, Wiltgen M, Hofmann-Wellenhof R, et al. Correlation of image analysis features and visual morphology in melanocytic skin tumours using in vivo confocal laser scanning microscopy. Skin Res Technol 2009; 15(2): 237-41. [http://dx.doi.org/10.1111/j.1600-0846.2009.00361.x] [PMID: 19622133]

[139] Pellacani G, De Pace B, Reggiani C, et al. Distinct melanoma types based on reflectance confocal microscopy. Exp Dermatol 2014; 23(6): 
414-8.

[http://dx.doi.org/10.1111/exd.12417] [PMID: 24750486]

[140] Stanganelli I, Longo C, Mazzoni L, et al. Integration of reflectance confocal microscopy in sequential dermoscopy follow-up improves melanoma detection accuracy. Br J Dermatol 2015; 172(2): 365-71. [http://dx.doi.org/10.1111/bjd.13373] [PMID: 25154446]

[141] Calzavara-Pinton P, Longo C, Venturini M, Sala R, Pellacani G. Reflectance confocal microscopy for in vivo skin imaging. Photochem Photobiol 2008; 84(6): 1421-30. [http://dx.doi.org/10.1111/j.1751-1097.2008.00443.x] [PMID: 19067964]

[142] Stevenson AD, Mickan S, Mallett S, Ayya M. Systematic review of diagnostic accuracy of reflectance confocal microscopy for melanoma diagnosis in patients with clinically equivocal skin lesions. Dermatol Pract Concept 2013; 3(4): 19-27. [http://dx.doi.org/10.5826/dpc.0304a05] [PMID: 24282659]

[143] Pellacani G, Cesinaro AM, Seidenari S. Reflectance-mode confocal microscopy of pigmented skin lesions--improvement in melanoma diagnostic specificity. J Am Acad Dermatol 2005; 53(6): 979-85. [http://dx.doi.org/10.1016/j.jaad.2005.08.022] [PMID: 16310058]

[144] de Carvalho N, Farnetani F, Ciardo S, et al. Reflectance confocal microscopy correlates of dermoscopic patterns of facial lesions help to discriminate lentigo maligna from pigmented nonmelanocytic macules. Br J Dermatol 2015; 173(1): 128-33. [http://dx.doi.org/10.1111/bjd.13546] [PMID: 25413382]

[145] Nori S, Rius-Díaz F, Cuevas J, et al. Sensitivity and specificity of reflectance-mode confocal microscopy for in vivo diagnosis of basal cell carcinoma: A multicenter study. J Am Acad Dermatol 2004; 51(6): 923-30. [http://dx.doi.org/10.1016/j.jaad.2004.06.028] [PMID: 15583584]

[146] Que SKT, Grant-Kels JM, Longo C, Pellacani G. Basics of confocal microscopy and the complexity of diagnosing skin tumors: New imaging tools in clinical practice, diagnostic workflows, cost-estimate, and New trends. Dermatol Clin 2016; 34(4): $367-75$. [http://dx.doi.org/10.1016/j.det.2016.05.001] [PMID: 27692444]

[147] Que SKT, Grant-Kels JM, Rabinovitz HS, Oliviero M, Scope A. Application of handheld confocal microscopy for skin cancer diagnosis: Advantages and limitations compared with the wide-probe confocal. Dermatol Clin 2016; 34(4): 469-75. [http://dx.doi.org/10.1016/j.det.2016.05.009] [PMID: 27692452]

[148] Song E, Grant-Kels JM, Swede H, et al. Paired comparison of the sensitivity and specificity of multispectral digital skin lesion analysis and reflectance confocal microscopy in the detection of melanoma in vivo: A cross-sectional study. J Am Acad Dermatol 2016; 75(6): 1187-1192.e2. [http://dx.doi.org/10.1016/j.jaad.2016.07.022] [PMID: 27693007]

[149] Holder WD Jr, White RL Jr, Zuger JH, Easton EJ Jr, Greene FL. Effectiveness of positron emission tomography for the detection of melanoma metastases. Ann Surg 1998; 227(5): 764-9. [http://dx.doi.org/10.1097/00000658-199805000-00017] [PMID: 9605668]

[150] Perng P, Marcus C, Subramaniam RM. (18)F-FDG PET/CT and Melanoma: Staging, Immune Modulation and Mutation-Targeted Therapy Assessment, and Prognosis. AJR Am J Roentgenol 2015; 205(2): 259-70. [http://dx.doi.org/10.2214/AJR.14.13575] [PMID: 26204273]

[151] Bronstein Y, Ng CS, Rohren E, et al. PET/CT in the management of patients with stage IIIC and IV metastatic melanoma considered candidates for surgery: Evaluation of the additive value after conventional imaging. AJR Am J Roentgenol 2012; 198(4): 902-8. [http://dx.doi.org/10.2214/AJR.11.7280] [PMID: 22451559]

[152] Strobel K, Dummer R, Husarik DB, Pérez Lago M, Hany TF, Steinert HC. High-risk melanoma: accuracy of FDG PET/CT with added CT morphologic information for detection of metastases. Radiology 2007; 244(2): 566-74. [http://dx.doi.org/10.1148/radiol.2442061099] [PMID: 17641374]

[153] Reinhardt MJ, Joe AY, Jaeger U, et al. Diagnostic performance of whole body dual modality 18F-FDG PET/CT imaging for N- and Mstaging of malignant melanoma: Experience with 250 consecutive patients. J Clin Oncol 2006; 24(7): 1178-87. [http://dx.doi.org/10.1200/JCO.2005.03.5634] [PMID: 16505438]

[154] Danielsen M, Højgaard L, Kjær A, Fischer BM. Positron emission tomography in the follow-up of cutaneous malignant melanoma patients: A systematic review. Am J Nucl Med Mol Imaging 2013; 4(1): 17-28. [PMID: 24380042]

[155] Veit-Haibach P, Vogt FM, Jablonka R, et al. Diagnostic accuracy of contrast-enhanced FDG-PET/CT in primary staging of cutaneous malignant melanoma. Eur J Nucl Med Mol Imaging 2009; 36(6): 910-8. [http://dx.doi.org/10.1007/s00259-008-1049-x] [PMID: 19156409]

[156] Huang D, Swanson EA, Lin CP, et al. Optical coherence tomography. Science 1991; 254(5035): $1178-81$. [http://dx.doi.org/10.1126/science.1957169] [PMID: 1957169]

[157] Boppart SA, Brezinski ME, Pitris C, Fujimoto JG. Optical coherence tomography for neurosurgical imaging of human intracortical melanoma. Neurosurgery 1998; 43(4): 834-41. [http://dx.doi.org/10.1097/00006123-199810000-00068] [PMID: 9766311]

[158] Fujimoto JG, Pitris C, Boppart SA, Brezinski ME. Optical coherence tomography: an emerging technology for biomedical imaging and optical biopsy. Neoplasia 2000; 2(1-2): 9-25. 
[http://dx.doi.org/10.1038/sj.neo.7900071] [PMID: 10933065]

[159] Welzel J. Optical coherence tomography in dermatology: A review. Skin Res Technol 2001; 7(1): 1-9. [http://dx.doi.org/10.1034/j.1600-0846.2001.007001001.x] [PMID: 11301634]

[160] Schuh S, Kaestle R, Sattler E, Welzel J. Comparison of different optical coherence tomography devices for diagnosis of non-melanoma skin cancer. Skin Res Technol 2016; 22(4): 395-405. [http://dx.doi.org/10.1111/srt.12277] [PMID: 26804618]

[161] Olsen J, Themstrup L, Jemec GB. Optical coherence tomography in dermatology. G Ital Dermatol Venereol 2015; 150(5): 603-15. [PMID: 26129683]

[162] Marx HF, Colletti PM, Raval JK, Boswell WD Jr, Zee C-S. Magnetic resonance imaging features in melanoma. Magn Reson Imaging 1990; 8(3): 223-9.

[http://dx.doi.org/10.1016/0730-725X(90)90093-H] [PMID: 2366635]

[163] Takahashi M, Kohda H. Diagnostic utility of magnetic resonance imaging in malignant melanoma. J Am Acad Dermatol 1992; 27(1): 51-4. [http://dx.doi.org/10.1016/0190-9622(92)70155-9] [PMID: 1619076]

[164] Zemtsov A, Dixon L. Magnetic resonance in dermatology. Arch Dermatol 1993; 129(2): 215-8. [http://dx.doi.org/10.1001/archderm.1993.01680230099015] [PMID: 8434981]

[165] Patwardhan SV, Dai S, Dhawan AP. Multi-spectral image analysis and classification of melanoma using fuzzy membership based partitions. Comput Med Imaging Graph 2005; 29(4): 287-96.

[http://dx.doi.org/10.1016/j.compmedimag.2004.11.001] [PMID: 15890256]

[166] Elbaum M, Kopf AW, Rabinovitz HS, et al. Automatic differentiation of melanoma from melanocytic nevi with multispectral digital dermoscopy: a feasibility study. J Am Acad Dermatol 2001; 44(2): 207-18. [http://dx.doi.org/10.1067/mjd.2001.110395] [PMID: 11174377]

[167] Kuzmina I, Diebele I, Jakovels D, Spigulis J, Valeine L, Kapostinsh J, et al. Towards noncontact skin melanoma selection by multispectral imaging analysis J Biomed Opt 2011; 16 [http://dx.doi.org/10.1117/1.3584846]

[168] Tomatis S, Carrara M, Bono A, et al. Automated melanoma detection with a novel multispectral imaging system: results of a prospective study. Phys Med Biol 2005; 50(8): 1675-87.

[http://dx.doi.org/10.1088/0031-9155/50/8/004] [PMID: 15815089]

[169] Zhou Y, Wang LV. Chapter 24 - Photoacoustic Tomography in the Diagnosis of Melanoma In: Imaging in Dermatology, P. Avci and G. K. Gupta, Eds., ed Boston: Academic Press, 2016, pp. 341-356.

[170] Bourgeois AC, Pasiak AS, Bradley YC. Chapter 32 - The role of positron emission tomography/computed tomography in cutaneous melanoma In: imaging in dermatology, P. Avci and G. K. Gupta, Eds., ed Boston: Academic Press, 2016, pp. 455-466.

[171] Sánchez-Sánchez R, Serrano-Falcón C, Rebollo Aguirre A C. Diagnostic imaging in dermatology: Utility of PET-CT in cutaneous melanoma Actas Dermosifiliogr 2015; 106(4): 29-34.

[172] Gambichler T, Regeniter P, Bechara FG, et al. Characterization of benign and malignant melanocytic skin lesions using optical coherence tomography in vivo. J Am Acad Dermatol 2007; 57(4): 629-37. [http://dx.doi.org/10.1016/j.jaad.2007.05.029] [PMID: 17610989]

[173] Wang Y, Xu D, Yang S, Xing D. Toward in vivo biopsy of melanoma based on photoacoustic and ultrasound dual imaging with an integrated detector. Biomed Opt Express 2016; 7(2): 279-86.

[http://dx.doi.org/10.1364/BOE.7.000279] [PMID: 26977339]

[174] Hoffmann K, Jung J, el Gammal S, Altmeyer P. Malignant melanoma in 20-MHz B scan sonography. Dermatology (Basel) 1992; 185(1): 49-55. [http://dx.doi.org/10.1159/000247403] [PMID: 1638071]

[175] Chami L, Lassau N, Chebil M, Robert C. Imaging of melanoma: Usefulness of ultrasonography before and after contrast injection for diagnosis and early evaluation of treatment. Clin Cosmet Investig Dermatol 2011; 4: 1-6. [PMID: 21673868]

[176] Mandava A, Ravuri PR, Konathan R. High-resolution ultrasound imaging of cutaneous lesions. Indian J Radiol Imaging 2013; 23(3): 269-77. [http://dx.doi.org/10.4103/0971-3026.120272] [PMID: 24347861]

[177] Wortsman X. Sonography of the Primary Cutaneous Melanoma: A Review. In: Radiol Res Pract 2012; Vol. 2012.

[178] Samimi M, Perrinaud A, Naouri M, et al. High-resolution ultrasonography assists the differential diagnosis of blue naevi and cutaneous metastases of melanoma. Br J Dermatol 2010; 163(3): 550-6. [http://dx.doi.org/10.1111/j.1365-2133.2010.09903.x] [PMID: 20545694]

[179] Serrone L, Solivetti FM, Thorel MF, Eibenschutz L, Donati P, Catricalà C. High frequency ultrasound in the preoperative staging of primary melanoma: A statistical analysis. Melanoma Res 2002; 12(3): 287-90. [http://dx.doi.org/10.1097/00008390-200206000-00013] [PMID: 12140386]

[180] Blum A, Schmid-Wendtner MH, Mauss-Kiefer V, Eberle JY, Kuchelmeister C, Dill-Müller D. Ultrasound mapping of lymph node and subcutaneous metastases in patients with cutaneous melanoma: results of a prospective multicenter study. Dermatology (Basel) 2006; 212(1): 
47-52.

[http://dx.doi.org/10.1159/000089022] [PMID: 16319474]

[181] Vasefi F, MacKinnon N, Farkas DL. Chapter 16 - hyperspectral and multispectral imaging in dermatology In: Imaging in Dermatology, P. Avci and G. K. Gupta, Eds., ed Boston: Academic Press, 2016, pp. 187-201.

[182] Ho D, Kraeva E, Jagdeo J, Levenson RM. Chapter 18 - spectral imaging in dermatology In: Imaging in Dermatology, P. Avci and G. K. Gupta, Eds., ed Boston: Academic Press, 2016, pp. 217-239.

[183] Bonmarin M, Le Gal FA. Chapter 31 - thermal imaging in dermatology In: Imaging in Dermatology, P. Avci and G. K. Gupta, Eds., ed Boston: Academic Press, 2016, pp. 437-454.

[184] Shada AL, Dengel LT, Petroni GR, Smolkin ME, Acton S, Slingluff CL Jr. Infrared thermography of cutaneous melanoma metastases. J Surg Res 2013; 182(1): e9-e14.

[http://dx.doi.org/10.1016/j.jss.2012.09.022] [PMID: 23043862]

[185] Herman C. The role of dynamic infrared imaging in melanoma diagnosis. Expert Rev Dermatol 2013; 8(2): $177-84$. [http://dx.doi.org/10.1586/edm.13.15] [PMID: 23745131]

[186] Cristofolini M, Boi S, Perani B, Recchia G, Zumiani G. Value of thermography in the diagnosis of malignant melanomas of the skin In: recent advances in medical thermology, E. F. J. Ring and B. Phillips, Eds., ed Boston, MA: Springer New York, 1984, pp. 631-634.

[187] Doukas C, Stagkopoulos P, Maglogiannis I. Skin lesions image analysis utilizing smartphones and cloud platforms. Methods Mol Biol 2015; 1256: 435-58.

[http://dx.doi.org/10.1007/978-1-4939-2172-0_29] [PMID: 25626556]

[188] Janda M, Loescher LJ, Banan P, Horsham C, Soyer HP. Lesion selection by melanoma high-risk consumers during skin self-examination using mobile teledermoscopy. JAMA Dermatol 2014; 150(6): 656-8. [http://dx.doi.org/10.1001/jamadermatol.2013.7743] [PMID: 24522284]

[189] Xing Y, Bronstein Y, Ross MI, et al. Contemporary diagnostic imaging modalities for the staging and surveillance of melanoma patients: A meta-analysis. J Natl Cancer Inst 2011; 103(2): 129-42. [http://dx.doi.org/10.1093/jnci/djq455] [PMID: 21081714]

[190] Malvehy J, Puig S. Follow-up of melanocytic skin lesions with digital total-body photography and digital dermoscopy: A two-step method. Clin Dermatol 2002; 20(3): 297-304. [http://dx.doi.org/10.1016/S0738-081X(02)00220-1] [PMID: 12074871]

[191] Mohr P, Eggermont AMM, Hauschild A, Buzaid A. Staging of cutaneous melanoma. Ann Oncol 2009; 20(Suppl. 6): vi14-21. [http://dx.doi.org/10.1093/annonc/mdp256] [PMID: 19617293]

[192] He J, Wang N, Tsurui H, Kato M, Iida M, Kobayashi T. Noninvasive, label-free, three-dimensional imaging of melanoma with confocal photothermal microscopy: Differentiate malignant melanoma from benign tumor tissue. Sci Rep 2016; 6: 30209. [http://dx.doi.org/10.1038/srep30209] [PMID: 27445171]

[193] Gómez DD, Butakoff C, Ersbøll BK, Stoecker W. Independent histogram pursuit for segmentation of skin lesions. IEEE Trans Biomed Eng 2008; 55(1): 157-61. [http://dx.doi.org/10.1109/TBME.2007.910651] [PMID: 18232357]

[194] Okuboyejo DA, Olugbara OO, Odunaike SA. Unsupervised Restoration of Hair-Occluded Lesion in Dermoscopic Images 18th Conference on Medical Image Understanding and Analysis. London, United Kingdom. 2014; pp. 91-6.

[195] Abbas Q, Garcia IF, Emre Celebi M, Ahmad W, Mushtaq Q. A perceptually oriented method for contrast enhancement and segmentation of dermoscopy images. Skin Res Technol 2013; 19(1): e490-7. [http://dx.doi.org/10.1111/j.1600-0846.2012.00670.x] [PMID: 22882675]

[196] Garnavi R, Aldeen M, Celebi ME, Bhuiyan A, Dolianitis C, Varigos G. Automatic segmentation of dermoscopy images using histogram thresholding on optimal color channels. IEEE J Transl Eng Health Med 2010; 1: 126-34.

[197] Hoshyar AN, Al-Jumaily A, Hoshyar AN. The Beneficial Techniques in Preprocessing Step of Skin Cancer Detection System Comparing. Procedia Comput Sci 2014; 42: 25-31

[http://dx.doi.org/10.1016/j.procs.2014.11.029]

[198] Rahman MM, Bhattacharya P, Desai BC. A multiple expert-based melanoma recognition system for dermoscopic images of pigmented skin lesions 8th IEEE International Conference on BioInformatics and BioEngineering (BIBE). 1-6. [http://dx.doi.org/10.1109/BIBE.2008.4696799]

[199] Quigley EA, Tokay BA, Jewell ST, Marchetti MA, Halpern AC. Technology and technique standards for camera-acquired digital dermatologic images: A systematic review. JAMA Dermatol 2015; 151(8): 883-90. [http://dx.doi.org/10.1001/jamadermatol.2015.33] [PMID: 25970844]

[200] Quintana J, Garcia R, Neumann L. A novel method for color correction in epiluminescence microscopy. Comput Med Imaging Graph 2011; 35(7-8): 646-52.

[http://dx.doi.org/10.1016/j.compmedimag.2011.03.006] [PMID: 21531539]

[201] Iyatomi H, Celebi ME, Schaefer G, Tanaka M. Automated color calibration method for dermoscopy images. Comput Med Imaging Graph 2011; 35(2): 89-98. [http://dx.doi.org/10.1016/j.compmedimag.2010.08.003] [PMID: 20933366] 
[202] Glaister J, Amelard R, Wong A, Clausi DA. MSIM: multistage illumination modeling of dermatological photographs for illuminationcorrected skin lesion analysis. IEEE Trans Biomed Eng 2013; 60(7): 1873-83. [http://dx.doi.org/10.1109/TBME.2013.2244596] [PMID: 23380843]

[203] Glaister J, Wong A, Clausi DA. Illumination Correction in Dermatological Photographs using Multi-stage Illumination Modeling for Skin Lesion Analysis $34^{\text {th }}$ Annual International Conference of the IEEE Engineering in Medicine and Biology Society (EMBS). San Diego, California USA. 2012; pp. 102-5. [http://dx.doi.org/10.1109/EMBC.2012.6345881]

[204] Grana C, Pellacani G, Seidenari S. Practical color calibration for dermoscopy, applied to a digital epiluminescence microscope. Skin Res Technol 2005; 11(4): 242-7. [http://dx.doi.org/10.1111/j.0909-725X.2005.00127.x] [PMID: 16221140]

[205] Wighton P, Lee TK, Lui H, McLean D, Atkins MS. Chromatic aberration correction: An enhancement to the calibration of low-cost digital dermoscopes. Skin Res Technol 2011; 17(3): 339-47. [http://dx.doi.org/10.1111/j.1600-0846.2011.00504.x] [PMID: 21338405]

[206] Schaefer G, Rajab MI, Celebi ME, Iyatomi H. Colour and contrast enhancement for improved skin lesion segmentation. Comput Med Imaging Graph 2011; 35(2): 99-104. [http://dx.doi.org/10.1016/j.compmedimag.2010.08.004] [PMID: 21035303]

[207] Okuboyejo DA, Olugbara OO, Odunaike SA. CLAHE Inspired Segmentation of Dermoscopic Images Using Mixture of Methods In: Transactions on Engineering Technologies, H. K. Kim, S.-I. Ao, and M. A. Amouzegar, Eds., ed: Springer Netherlands, 2014 , pp. $355-365$.

[208] Premaladha J, Ravichandran KS. Novel approaches for diagnosing melanoma skin lesions through supervised and deep learning algorithms. J Med Syst 2016; 40(4): 96. [http://dx.doi.org/10.1007/s10916-016-0460-2] [PMID: 26872778]

[209] Abbas Q, Garcia IF, Emre Celebi M, Ahmad W. A feature-preserving hair removal algorithm for dermoscopy images. Skin Res Technol 2013; 19(1): e27-36.

[http://dx.doi.org/10.1111/j.1600-0846.2011.00603.x] [PMID: 22211360]

[210] Kiani K, Sharafat AR. E-shaver: An improved DullRazor $\left({ }^{\circledR}\right)$ for digitally removing dark and light-colored hairs in dermoscopic images. Comput Biol Med 2011; 41(3): 139-45. [http://dx.doi.org/10.1016/j.compbiomed.2011.01.003] [PMID: 21316042]

[211] Abbas Q, Fondón I, Rashid M. Unsupervised skin lesions border detection via two-dimensional image analysis. Comput Methods Programs Biomed 2011; 104(3): e1-e15. [http://dx.doi.org/10.1016/j.cmpb.2010.06.016] [PMID: 20663582]

[212] Nguyen NH, Lee TK, Atkins MS. Segmentation of light and dark hair in dermoscopic images: A hybrid approach using a universal kernel. In: Proceedings of SPIE 7623. Medical Imaging 2010; pp. 76234N-76234N, 8.

[213] Lee T, Ng V, Gallagher R, Coldman A, McLean D. DullRazor: a software approach to hair removal from images. Comput Biol Med 1997; 27(6): 533-43.

[http://dx.doi.org/10.1016/S0010-4825(97)00020-6] [PMID: 9437554]

[214] Xie F-Y, Qin S-Y, Jiang Z-G, Meng R-S. PDE-based unsupervised repair of hair-occluded information in dermoscopy images of melanoma. Comput Med Imaging Graph 2009; 33(4): 275-82. [http://dx.doi.org/10.1016/j.compmedimag.2009.01.003] [PMID: 19261439]

[215] Zhou H, Rehg JM, Chen M. Exemplar-Based Segmentation of Pigmented Skin Lesions from Dermoscopy Images International Symposium on Biomedical Imaging (ISBI). [http://dx.doi.org/10.1109/ISBI.2010.5490372]

[216] Wighton P, Lee TK, Atkins MS. Dermascopic hair disocclusion using inpainting.Proceeding of SPIE 6914. Medical Imaging 2008. [http://dx.doi.org/10.1117/12.770776]

[217] Koehoorn J, Sobiecki A, Rauber P, Jalba A, Telea A. Efficient and effective automated digital hair removal from dermoscopy images. mathematical morphology - theory and Applications 2015; Vol. 1: pp. 1-17.

[218] Criminisi A, Pérez P, Toyama K. Region filling and object removal by exemplar-based image inpainting. IEEE Trans Image Process 2004; 13(9): 1200-12. [http://dx.doi.org/10.1109/TIP.2004.833105] [PMID: 15449582]

[219] Chung DH, Sapiro G. Segmenting skin lesions with partial-differential-equations-based image processing algorithms. IEEE Trans Med Imaging 2000; 19(7): 763-7.

[http://dx.doi.org/10.1109/42.875204] [PMID: 11055791]

[220] Fiorese M, Peserico E, Silletti A. VirtualShave: Automated hair removal from digital dermatoscopic images Annual International Conference of the IEEE Engineering in Medicine and Biology Society (EMBC). 5145-8. [http://dx.doi.org/10.1109/IEMBS.2011.6091274]

[221] Oliveira RB, Filho ME, Ma Z, Papa JP, Pereira AS, Tavares JMRS. Computational methods for the image segmentation of pigmented skin lesions: A review. Comput Methods Programs Biomed 2016; 131: 127-41. [http://dx.doi.org/10.1016/j.cmpb.2016.03.032] [PMID: 27265054] 
[222] Sumithra R, Suhil M, Guru DS. Segmentation and classification of skin lesions for disease diagnosis In: Procedia Comput Sci. 2015; 45: pp. $76-85$.

[223] Mehta P, Shah B. Review on techniques and steps of computer aided skin cancer diagnosis. Procedia Comput Sci 2016; 85: $309-16$. [http://dx.doi.org/10.1016/j.procs.2016.05.238]

[224] Giotis I, Molders N, Land S, Biehl M, Jonkman MF, Petkov N. MED-NODE: A computer-assisted melanoma diagnosis system using nondermoscopic images. Expert Syst Appl 2015; 42: 6578-85. [http://dx.doi.org/10.1016/j.eswa.2015.04.034]

[225] Xie F, Li Y, Meng R, Jiang Z. No-reference hair occlusion assessment for dermoscopy images based on distribution feature. Comput Biol Med 2015; 59: 106-15. [http://dx.doi.org/10.1016/j.compbiomed.2015.01.023] [PMID: 25701625]

[226] Wang H, Moss RH, Chen X, et al. Modified watershed technique and post-processing for segmentation of skin lesions in dermoscopy images. Comput Med Imaging Graph 2011; 35(2): 116-20. [http://dx.doi.org/10.1016/j.compmedimag.2010.09.006] [PMID: 20970307]

[227] Afonso A, Silveira M. Hair detection in dermoscopic images using Percolation 34th Annual International Conference of the IEEE Engineering in Medisine and Biology Society (EMBS). San Diego, California USA. 2012. [http://dx.doi.org/10.1109/EMBC.2012.6346936]

[228] Toossi MTB, Pourreza HR, Zare H, Sigari M-H, Layegh P, Azimi A. An effective hair removal algorithm for dermoscopy images. Skin Res Technol 2013; 19(3): 230-5. [http://dx.doi.org/10.1111/srt.12015] [PMID: 23560826]

[229] Suer S, Kockara S, Mete M. An improved border detection in dermoscopy images for density based clustering. BMC Bioinformatics 2011; 12(Suppl. 10): S12. [http://dx.doi.org/10.1186/1471-2105-12-S10-S12] [PMID: 22166058]

[230] Mete M, Kockara S, Aydin K. Fast density-based lesion detection in dermoscopy images. Comput Med Imaging Graph 2011; 35 (2): 128-36. [http://dx.doi.org/10.1016/j.compmedimag.2010.07.007] [PMID: 20800995]

[231] Celebi ME, Iyatomi H, Schaefer G, Stoecker WV. Lesion border detection in dermoscopy images. Comput Med Imaging Graph 2009; 33(2): $148-53$.

[http://dx.doi.org/10.1016/j.compmedimag.2008.11.002] [PMID: 19121917]

[232] Silletti A, Peserico E, Mantovan A, Zattra E, Peserico A, Belloni Fortina A. Variability in human and automatic segmentation of melanocytic lesions 31st Annual International Conference of the IEEE Engineering in Medicine and Biology Society (EMBS). Minneapolis, Minnesota, USA. 2009; pp. 5789-92.

[http://dx.doi.org/10.1109/IEMBS.2009.5332543]

[233] Abbas Q, Celebi ME, Fondón García I, Rashid M. Lesion border detection in dermoscopy images using dynamic programming. Skin Res Technol 2011; 17(1): 91-100. [http://dx.doi.org/10.1111/j.1600-0846.2010.00472.x] [PMID: 21226876]

[234] Abbas Q, Celebi ME, Fondón García I. Skin tumor area extraction using an improved dynamic programming approach. Skin Res Technol $2012 ; 18(2): 133-42$. [http://dx.doi.org/10.1111/j.1600-0846.2011.00544.x] [PMID: 21507072]

[235] Cudek P, Grzymala-Busse JW, Hippe ZW. Melanocytic Skin Lesion Image Classification. Part I: Recognition of Skin Lesion International Conference on Human System Interactions (HSI). Rzeszow, Poland. 2010. [http://dx.doi.org/10.1109/HSI.2010.5514558]

[236] Barhoumi W, Dhahbi S, Zagrouba E. A Collaborative System for Pigmented Skin Lesions Malignancy Tracking IEEE International Workshop on Imaging Systems and Techniques (IST). Krakow, Poland. 2007.May 4-5, 2007; [http://dx.doi.org/10.1109/IST.2007.379576]

[237] Joel G, Schmid-Saugeon P, Guggisberg D, et al. Validation of segmentation techniques for digital dermoscopy. Skin Res Technol 2002; 8(4): 240-9. [http://dx.doi.org/10.1034/j.1600-0846.2002.00334.x] [PMID: 12423543]

[238] Zhou H, Schaefer G, Sadka AH, Celebi ME. Anisotropic Mean Shift Based Fuzzy C-Means Segmentation of Dermoscopy Images. IEEE J Sel Top Signal Process 2009; 3: 26-34.

[http://dx.doi.org/10.1109/JSTSP.2008.2010631]

[239] Chang W-Y, Huang A, Chen Y-C, et al. The feasibility of using manual segmentation in a multifeature computer-aided diagnosis system for classification of skin lesions: a retrospective comparative study. BMJ Open 2015; 5(4): e007823. [http://dx.doi.org/10.1136/bmjopen-2015-007823] [PMID: 25941190]

[240] Abbas AA, Guo X, Tan WH, Jalab HA. Combined Spline and B-spline for an improved automatic skin lesion segmentation in dermoscopic images using optimal color channel. J Med Syst 2014; 38(8): 80. [http://dx.doi.org/10.1007/s10916-014-0080-7] [PMID: 24957396]

[241] Messadi M, Bessaid A, Taleb-Ahmed A. Extraction of specific parameters for skin tumour classification. J Med Eng Technol 2009; 33(4): 288-95. 
[http://dx.doi.org/10.1080/03091900802451315] [PMID: 19384704]

[242] Fischer S, Schmid P, Guillod J. Analysis of skin lesions with pigmented networks Proceedings, International Conference on Image Processing. 323-6.

[http://dx.doi.org/10.1109/ICIP.1996.559498]

[243] Taouil K, Romdhane NB. Automatic Segmentation and classification of Skin Lesion Images The 2nd International Conference on Distributed Frameworks for Multimedia Applications. 1-12. [http://dx.doi.org/10.1109/DFMA.2006.296918]

[244] Glaister J, Wong A, Clausi DA. Segmentation of skin lesions from digital images using joint statistical texture distinctiveness. IEEE Trans Biomed Eng 2014; 61(4): 1220-30. [http://dx.doi.org/10.1109/TBME.2013.2297622] [PMID: 24658246]

[245] Dhawan AP, Sicsu A. Segmentation of images of skin lesions using color and texture information of surface pigmentation. Comput Med Imaging Graph 1992; 16(3): 163-77.

[http://dx.doi.org/10.1016/0895-6111(92)90071-G] [PMID: 1623492]

[246] Serrano C, Acha B. Pattern analysis of dermoscopic images based on Markov random fields. Pattern Recognit 2009; 42: 1052-7. [http://dx.doi.org/10.1016/j.patcog.2008.07.011]

[247] Xu L, Jackowski M, Goshtasby A, Roseman D, Bines S, Yu C, et al. Segmentation of skin cancer images. Image Vis Comput 1999; 17 : 65-74.

[http://dx.doi.org/10.1016/S0262-8856(98)00091-2]

[248] Hwang S, Celebi ME. Texture segmentation of dermoscopy images using Gabor filters and g-means clustering Proceedings of the International Conference on Image Processing, Computer Vision, and Pattern Recognition (IPCV). 882-6.

[249] Flores E, Scharcanski J. Segmentation of melanocytic skin lesions using feature learning and dictionaries. Expert Syst Appl 2016; 56: 300-9. [http://dx.doi.org/10.1016/j.eswa.2016.02.044]

[250] Ming D, Wen Q, Chen J, Liu W. A generalized fusion approach for segmenting dermoscopy images using Markov random field 6th International Congress on Image and Signal Processing (CISP). 532-7.

[http://dx.doi.org/10.1109/CISP.2013.6744054]

[251] Maeda J, Kawano A, Yamauchi S, Suzuki Y, Marçal A, Mendonça T. Perceptual image segmentation using fuzzy-based hierarchical algorithm and its application to dermoscopy images IEEE Conference on Soft Computing in Industrial Applications (SMCia/08). Muroran, Japan. 2008; pp. 66-71.

[http://dx.doi.org/10.1109/SMCIA.2008.5045937]

[252] Madhankumar K, Kumar P. Characterization of skin lesions International Conference on Pattern Recognition, Informatics and Medical Engineering (PRIME). 302-6. [http://dx.doi.org/10.1109/ICPRIME.2012.6208362]

[253] Parolin A, Herzer E, Jung CR. Semi-automated diagnosis of melanoma through the analysis of dermatological images $23^{\text {rd }}$ Conference on Graphics, Patterns and Images (SIBGRAPI). 71-8.

[http://dx.doi.org/10.1109/SIBGRAPI.2010.18]

[254] Barcelos CAZ, Pires VB. An automatic based nonlinear diffusion equations scheme for skin lesion segmentation. Appl Math Comput 2009; 215: 251-61.

[http://dx.doi.org/10.1016/j.amc.2009.04.081]

[255] Pires VB, Barcelos CAZ. Edge detection of skin lesions using anisotropic diffusion seventh international conference on intelligent systems design and applications. [http://dx.doi.org/10.1109/ISDA.2007.139]

[256] Canny J. A Computational Approach to Edge Detection In: IEEE Trans Pattern Anal Mach Intell. 1986; vol. PAMI-8.

[257] Prewitt JMS. Object enhancement and extraction In: Picture Processing and Psychopictorics, B. Lipkin and A. Rosenfeld, Eds., ed New York: Academic Press, 1970, pp. 75-49.

[258] Sobel I, Feldman G. A 3x3 isotropic gradient operator for image processing In: Pattern Classification and Scene Analysis,, R. Duda and P. Hart, Eds., ed: John Wiley \& Sons, 1968, pp. 271-272.

[259] Kirsch RA. Computer determination of the constituent structure of biological images. Comput Biomed Res 1971; 4(3): 315-28. [http://dx.doi.org/10.1016/0010-4809(71)90034-6] [PMID: 5562571]

[260] Yasmin JHJ, Sathik MM, Beevi SZ. Robust Segmentation Algorithm using LOG Edge Detector for Effective Border Detection of Noisy Skin Lesions International Conference on Computer, Communication and Electrical Technology. 60-5.

[261] Cavalcanti PG, Scharcanski J. A coarse-to-fine approach for segmenting melanocytic skin lesions in standard camera images. Comput Methods Programs Biomed 2013; 112(3): 684-93. [http://dx.doi.org/10.1016/j.cmpb.2013.08.010] [PMID: 24075079]

[262] Celebi ME, Aslandogan YA, Bergstresser PR. Unsupervised Border Detection of Skin Lesion Images International Conference on Information Technology: Coding and Computing (ITCC).

[http://dx.doi.org/10.1109/ITCC.2005.283] 
[263] Nourmohamadi M, Pourghassem H. Dermoscopy Image Segmentation Using a Modified Level Set algorithm 4th International Conference on Computational Intelligence and Communication Networks. 286-90. [http://dx.doi.org/10.1109/CICN.2012.80]

[264] Silveira M, Marques JS. Level Set Segmentation of Dermoscopy Images The International Symposium on Biomedical Imaging (ISBI). 173-6.

[265] Situ N, Yuan X, Zouridakis G, Mullani N. Automatic Segmentation of Skin Lesion Images Using Evolutionary Strategy The International Conference on Image Processing (ICIP). [http://dx.doi.org/10.1109/ICIP.2007.4379575]

[266] Wong A, Scharcanski J, Fieguth P. Automatic skin lesion segmentation via iterative stochastic region merging. IEEE Trans Inf Technol Biomed 2011; 15(6): 929-36. [http://dx.doi.org/10.1109/TITB.2011.2157829] [PMID: 21622078]

[267] Jaworek-Korjakowska J. Novel method for border irregularity assessment in dermoscopic color images. Comput Math Methods Med 2015; 2015: 496202. [http://dx.doi.org/10.1155/2015/496202] [PMID: 26604980]

[268] Emre Celebi M, Alp Aslandogan Y, Stoecker WV, Iyatomi H, Oka H, Chen X. Unsupervised border detection in dermoscopy images. Skin Res Technol 2007; 13(4): 454-62. [http://dx.doi.org/10.1111/j.1600-0846.2007.00251.x] [PMID: 17908199]

[269] Celebi ME, Kingravi HA, Iyatomi H, et al. Border detection in dermoscopy images using statistical region merging. Skin Res Technol 2008; 14(3): 347-53. [http://dx.doi.org/10.1111/j.1600-0846.2008.00301.x] [PMID: 19159382]

[270] Celebi ME, Kingravi HA, Iyatomi H, Lee J, Aslandogan YA, Van Stoecker W, et al. Fast and accurate border detection in dermoscopy images using statistical region merging. In: Proceeding of SPIE 6512. Medical Imaging 2007; pp. 65123V-65123V, 10. [http://dx.doi.org/10.1117/12.709073]

[271] Wang H, Chen X, Moss RH, et al. Watershed segmentation of dermoscopy images using a watershed technique. Skin Res Technol 2010; 16(3): 378-84. [PMID: 20637008]

[272] Pennisi A, Bloisi DD, Nardi D, Giampetruzzi AR, Mondino C, Facchiano A. Skin lesion image segmentation using Delaunay Triangulation for melanoma detection. Comput Med Imaging Graph 2016; 52: 89-103. [http://dx.doi.org/10.1016/j.compmedimag.2016.05.002] [PMID: 27215953]

[273] Ma Z, Tavares JMRS. A novel approach to segment skin lesions in dermoscopic images based on a deformable model. IEEE J Biomed Health Inform 2016; 20(2): 615-23. [http://dx.doi.org/10.1109/JBHI.2015.2390032] [PMID: 25585429]

[274] Euijoon Ahn, Lei Bi, Jinman Kim, Changyang Li , Fulham M, Feng DD. Automated saliency-based lesion segmentation in dermoscopic images. Conf Proc IEEE Eng Med Biol Soc 2015; 2015: 3009-12. [PMID: 26736925]

[275] Olugbara OO, Taiwo TB, Heukelman D. Segmentation of melanoma skin lesion using perceptual color difference saliency with morphological analysis. Math Probl Eng 2018. [http://dx.doi.org/10.1155/2018/1524286]

[276] Mendonça T, Marçal ARS, Vieira A, Nascimento JC, Silveira M, Marques JS, et al. Comparison of Segmentation Methods for Automatic Diagnosis of Dermoscopy Images In: Conference of the IEEE Engineering in Medicine and Biology Society (EMBS), Cité Internationale, Lyon, France. 2007; pp. 6572-5. [http://dx.doi.org/10.1109/IEMBS.2007.4353865]

[277] Tang J. A multi-direction GVF snake for the segmentation of skin cancer images. Pattern Recognit 2009; 42: 1172-9. [http://dx.doi.org/10.1016/j.patcog.2008.09.007]

[278] Erkol B, Moss RH, Stanley RJ, Stoecker WV, Hvatum E. Automatic lesion boundary detection in dermoscopy images using gradient vector flow snakes. Skin Res Technol 2005; 11(1): 17-26. [http://dx.doi.org/10.1111/j.1600-0846.2005.00092.x] [PMID: 15691255]

[279] Zhou H, Li X, Schaefer G, Celebi ME, Miller P. Mean shift based gradient vector flow for image segmentation. Comput Vis Image Underst 2013; 117: 1004-16. [http://dx.doi.org/10.1016/j.cviu.2012.11.015]

[280] Zhou H, Schaefer G, Celebi ME, Lin F, Liu T. Gradient vector flow with mean shift for skin lesion segmentation. Comput Med Imaging Graph 2011; 35(2): 121-7. [http://dx.doi.org/10.1016/j.compmedimag.2010.08.002] [PMID: 20832242]

[281] Zhou H, Schaefer G, Celebi ME, Iyatomi H, Norton K-A, Liu T, et al. Skin lesion segmentation using an improved snake model 32nd Annual International Conference of the IEEE Engineering in Medicine and Biology Society (EMBS). 1974-7. [http://dx.doi.org/10.1109/IEMBS.2010.5627556]

[282] Sultana A, Ciuc M, Radulescu T, Liu W, Petrache D. Preliminary work on dermatoscopic lesion segmentation 20th European Signal Processing Conference (EUSIPCO). Bucharest, Romania. 2012; pp. 2273-7. 
[283] Silveira M, Nascimento JC, Marques JS, Marçal ARS, Mendonça T, Yamauchi S, et al. Comparison of segmentation methods for melanoma diagnosis in dermoscopy images. IEEE J Sel Top Signal Process 2009; 3: 35-45. [http://dx.doi.org/10.1109/JSTSP.2008.2011119]

[284] Yuan X, Situ N, Zouridakis G. A narrow band graph partitioning method for skin lesion segmentation. Pattern Recognit 2009; 42: 1017-28. [http://dx.doi.org/10.1016/j.patcog.2008.09.006]

[285] Zhang Z, Stoecker WV, Moss RH. Border detection on digitized skin tumor images. IEEE Trans Med Imaging 2000; 19(11): 1128-43. [http://dx.doi.org/10.1109/42.896789] [PMID: 11204850]

[286] Golston JE, Moss RH, Stoecker WV. Boundary detection in skin tumor images: An overall approach and a radial search algorithm. Pattern Recognit 1990; 23: 1235-47. [http://dx.doi.org/10.1016/0031-3203(90)90119-6]

[287] Mete M, Sirakov NM. Lesion detection in demoscopy images with novel density-based and active contour approaches. BMC Bioinformatics 2010; 11(Suppl. 6): S23. [http://dx.doi.org/10.1186/1471-2105-11-S6-S23] [PMID: 20946607]

[288] Ivanovici M, Stoica D. Color Diffusion Model for Active Contours - An Application to Skin Lesion Segmentation 34th Annual International Conference of the IEEE Engineering in Medicine and Biology Society (EMBS). San Diego, California USA. 2012; pp. 5347-50. [http://dx.doi.org/10.1109/EMBC.2012.6347202]

[289] Kasmi R, Mokrani K, Rader RK, Cole JG, Stoecker WV. Biologically inspired skin lesion segmentation using a geodesic active contour technique. Skin Res Technol 2016; 22(2): 208-22. [http://dx.doi.org/10.1111/srt.12252] [PMID: 26403797]

[290] Gioi RGv, Jakubowicz J, Morcel J-M, Randall G. LSD: A Line Segment Detectot. In: Image Processing On Line. 2012.

[291] Capdehourat G, Corez A, Bazzano A, Alonso R, Musé P. Toward a combined tool to assist dermatologists in melanoma detection from dermoscopic images of pigmented skin lesions. Pattern Recognit Lett 2011; 32: 2187-96. [http://dx.doi.org/10.1016/j.patrec.2011.06.015]

[292] Dalal A, Moss RH, Stanley RJ, et al. Concentric decile segmentation of white and hypopigmented areas in dermoscopy images of skin lesions allows discrimination of malignant melanoma. Comput Med Imaging Graph 2011; 35(2): 148-54. [http://dx.doi.org/10.1016/j.compmedimag.2010.09.009] [PMID: 21074971]

[293] Humayun J, Malik AS, Kamel N. Multilevel Thresholding for segmentation of pigmented skin lesions IEEE International Conference on Imaging Systems and Techniques (IST). [http://dx.doi.org/10.1109/IST.2011.5962214]

[294] Norton K-A, Iyatomi H, Celebi ME, Schaefer G, Tanaka M, Ogawa K. Development of a Novel Border Detection Method for Melanocytic and Non-Melanocytic Dermoscopy Images 32nd Annual International Conference of the IEEE Engineering in Medicine and Biology Society (EMBS). Buenos Aires, Argentina. 2010. [http://dx.doi.org/10.1109/IEMBS.2010.5626499]

[295] Sarrafzade O, Miran MH, Ghassemi P. Skin Lesion Detection in Dermoscopy Images Using Wavelet Transform and Morphology Operations 17 th Iranian Conference of Biomedical Engineering (ICBME).

[http://dx.doi.org/10.1109/ICBME.2010.5704944]

[296] Supot S. Border detection of skin lesion images based on fuzzy C-Means thresholding $3^{\text {rd }}$ International Conference on Genetic and Evolutionary Computing. 777-80.

[297] Yuksel ME, Borlu M. Accurate segmentation of dermoscopic images by image thresholding based on Type-2 fuzzy logic. IEEE Trans Fuzzy Syst 2009; 17: 976-82. [http://dx.doi.org/10.1109/TFUZZ.2009.2018300]

[298] Oliveira RB, Marranghello N, Pereira AS, Tavares JMRS. A computational approach for detecting pigmented skin lesions in macroscopic images. Expert Syst Appl 2016; 61: 53-63. [http://dx.doi.org/10.1016/j.eswa.2016.05.017]

[299] Rahman MM, Bhattacharya P. An integrated and interactive decision support system for automated melanoma recognition of dermoscopic images. Comput Med Imaging Graph 2010; 34(6): 479-86. [http://dx.doi.org/10.1016/j.compmedimag.2009.10.003] [PMID: 19942406]

[300] Sezgin M, Sankur B. Survey over image thresholding techniques and quantitative performance evaluation. J Electron Imaging 2004; 13: 146-65. [http://dx.doi.org/10.1117/1.1631315]

[301] Otsu N. A threshold selection method from gray-level histograms. IEEE Trans Syst Man Cybern 1979; 9: 62-6. [http://dx.doi.org/10.1109/TSMC.1979.4310076]

[302] Premaladha J, Priya ML, Sujitha S, Ravichandran KS. Normalised otsu's segmentation. Indian J Sci Technol 2015 ; 8: 1-6. [http://dx.doi.org/10.17485/ijst/2015/v8i22/79140]

[303] Abbas Q, Garcia IF, Emre Celebi M, Ahmad W, Mushtaq Q. Unified approach for lesion border detection based on mixture modeling and local entropy thresholding. Skin Res Technol 2013; 19(3): 314-9. [http://dx.doi.org/10.1111/srt.12047] [PMID: 23573804] 
[304] Celebi ME, Hwang S, Iyatomi H, Schaefer G. Robust border detection in dermoscopy images using threshold fusion IEEE International Conference on Image Processing. Hong Kong. 2010; pp. 2541-4. [http://dx.doi.org/10.1109/ICIP.2010.5653514]

[305] Celebi ME, Iyatomi H, Schaefer G, Stoecker WV. Approximate lesion localization in dermoscopy images. Skin Res Technol 2009; 15(3): 314-22. [http://dx.doi.org/10.1111/j.1600-0846.2009.00357.x] [PMID: 19624428]

[306] Cavalcanti PG, Yari Y, Scharcanski J. Pigmented Skin Lesion Segmentation on Macroscopic Images 25th International Conference of Image and Vision Computing New Zealand (IVCNZ). [http://dx.doi.org/10.1109/IVCNZ.2010.6148845]

[307] Lee H, Chen Y-PP. Skin cancer extraction with optimum fuzzy thresholding technique. Appl Intell 2014; 40: 415-26. [http://dx.doi.org/10.1007/s10489-013-0474-0]

[308] Wighton P, Sadeghi M, Lee TK, Atkins MS. A Fully Automatic Random Walker Segmentation for Skin Lesions in a Supervised Setting International Conference on Medical Image Computing and Computer Assisted Intervention (MICCAI). 1108-15. [http://dx.doi.org/10.1007/978-3-642-04271-3_134]

[309] Kapur JN, Sahoo PK, Wong AKC. A new method for gray-level picture thresholding using the entropy of the histogram In: Comput Vis Graph Image Process. 1985; vol. 29: pp. 273-85.

[310] Kittler J, Illingworth J. On threshold selection using clustering criteria. IEEE Trans Syst Man Cybern 1985; SMC-15: 652-5. [http://dx.doi.org/10.1109/TSMC.1985.6313443]

[311] Ridler TW, Calvard S. Picture Thresholding Using an Iterative Selection Method. IEEE Trans Syst Man Cybern 1978; 8: 630-2. [http://dx.doi.org/10.1109/TSMC.1978.4310039]

[312] Sahoo P, Wilkins C, Yeager J. Threshold selection using Renyi’s entropy. Pattern Recognit 1997; $30: 71-84$ [http://dx.doi.org/10.1016/S0031-3203(96)00065-9]

[313] Castillejos H, Ponomaryov V, Nino-de-Rivera L, Golikov V. Wavelet transform fuzzy algorithms for dermoscopic image segmentation Comput Math Methods Med 2012; 2012: 578721. [http://dx.doi.org/10.1155/2012/578721] [PMID: 22567042]

[314] Schmid P. Segmentation of digitized dermatoscopic images by two-dimensional color clustering. IEEE Trans Med Imaging 1999; 18(2): 164-71. [http://dx.doi.org/10.1109/42.759124] [PMID: 10232673]

[315] Liu Z, Sun J, Smith M, Smith L, Warr R. Unsupervised sub-segmentation for pigmented skin lesions. Skin Res Technol 2012 ; $18(1)$ : 77-87. [http://dx.doi.org/10.1111/j.1600-0846.2011.00534.x] [PMID: 21545650]

[316] Zhou H, Chen M, Zou L, Gass R, Ferris L, Drogowski L, et al. Spatially Constrained Segmentation of Dermoscopy Images International Symposium on Biomedical Imaging (ISBI).

[317] Khakabi S, Wighton P, Lee TK, Atkins MS. Multilevel feature extraction for skin lesion segmentation in dermoscopic images In: SPIE Medical Imaging. 2012. pp. 83150E-83150E-7.

[318] Celebi ME, Guo W, Aslandogan YA, Bergstresser PR. Skin Lesion Segmentation Using Clustering Techniques The Florida Artificial Intelligence Research Society Conference (FLAIRS). Florida, USA. 2005.

[319] Møllersen K, Kirchesch HM, Schopf TG, Godtliebsen F. Unsupervised segmentation for digital dermoscopic images. Skin Res Technol 2010; 16(4): 401-7.

[http://dx.doi.org/10.1111/j.1600-0846.2010.00455.x] [PMID: 20923456]

[320] Lemon J, Kockara S, Halic T, Mete M. Density-based parallel skin lesion border detection with webCL. BMC Bioinformatics 2015; 16(Suppl. 13): S5-5. [http://dx.doi.org/10.1186/1471-2105-16-S13-S5] [PMID: 26423836]

[321] Khalid S, Jamil U, Saleem K, et al. Segmentation of skin lesion using Cohen-Daubechies-Feauveau biorthogonal wavelet. Springerplus 2016; 5(1): 1603. [http://dx.doi.org/10.1186/s40064-016-3211-4] [PMID: 27652176]

[322] Sadri AR, Zekri M, Member S. segmentation of dermoscopy images using wavelet networks In: IEEE Trans Biomed Eng. 2013; 60: pp. 1134-41.

[323] Kockara S, Mete M, Yip V, Lee B, Aydin K. A soft kinetic data structure for lesion border detection. Bioinformatics 2010; 26(12): i21-8. [http://dx.doi.org/10.1093/bioinformatics/btq178] [PMID: 20529909]

[324] Melli R, Grana C, Cucchiara R. Comparison of color clustering algorithms for segmentation of dermatological images.Proceedings of SPIE 6144. San Diego, CA, USA: Medical Imaging 2006; pp. 61443S-61443S, 9. [http://dx.doi.org/10.1117/12.652061]

[325] Kockara S, Mete M, Chen B, Aydin K. Analysis of density based and fuzzy c-means clustering methods on lesion border extraction in dermoscopy images. BMC Bioinformatics 2010; 11(Suppl. 6): S26. [http://dx.doi.org/10.1186/1471-2105-11-S6-S26] [PMID: 20946610] 
[326] Kwasnicka H, Paradowski M. Melanocytic Lesion Images Segmentation Enforcing by Spatial Relations Based Declarative Knowledge 5th International Conference on Intelligent Systems Design and Applications (ISDA). [http://dx.doi.org/10.1109/ISDA.2005.63]

[327] Pereyra M, Dobigeon N, Batatia H, Tourneret J-Y. Segmentation of Skin Lesions in 2-D and 3-D Ultrasound Images Using a Spatially Coherent Generalized Rayleigh Mixture Model In: IEEE Trans Med Imaging. 2012; vol. 31: pp. 1509-20.

[328] Zhou Y, Smith M, Smith L, Warr R. Segmentation of Clinical Lesion Images Using Normalized Cut 10th Workshop on Image Analysis for Multimedia Interactive Services (WIAMIS). [http://dx.doi.org/10.1109/WIAMIS.2009.5031442]

[329] Zortea M, Skrøvseth SO, Schopf TR, Kirchesch HM, Godtliebsen F. Automatic segmentation of dermoscopic images by iterative classification. Int J Biomed Imaging 2011; 2011: 972648. [http://dx.doi.org/10.1155/2011/972648] [PMID: 21811493]

[330] Schaefer G, Rajab MI, Celebi ME, Iyatomi H. Skin lesion segmentation using co-operative neural network edge detection and colour normalisation 9th International Conference on Infomation Technology and Applications in Biomedicine (ITAB). Larnaca, Cyprus. 2009. [http://dx.doi.org/10.1109/ITAB.2009.5394389]

[331] Xie F, Bovik AC. Automatic segmentation of dermoscopy images using self-generating neural networks seeded by genetic algorithm. Pattern Recognit 2013; 46: 1012-9. [http://dx.doi.org/10.1016/j.patcog.2012.08.012]

[332] Vennila GS, Suresh LP, Shunmuganathan KL. Dermoscopic Image Segmentation and Classification using Machine Learning Algorithms International Conference on Computing, Electronics and Electrical Technologies (ICCEET). 1122-7. [http://dx.doi.org/10.1109/ICCEET.2012.6203834]

[333] Garnavi R, Aldeen M, Celebi ME, Varigos G, Finch S. Border detection in dermoscopy images using hybrid thresholding on optimized color channels. Comput Med Imaging Graph 2011; 35(2): 105-15. [http://dx.doi.org/10.1016/j.compmedimag.2010.08.001] [PMID: 20832992]

[334] Emre Celebi M, Wen Q, Hwang S, Iyatomi H, Schaefer G. Lesion border detection in dermoscopy images using ensembles of thresholding methods. Skin Res Technol 2013; 19(1): e252-8. [http://dx.doi.org/10.1111/j.1600-0846.2012.00636.x] [PMID: 22676490]

[335] Cavalcanti PG, Scharcanski J, Persia LED, Milone DH. An ICA-Based Method for the Segmentation of Pigmented Skin Lesions in Macroscopic Images 33rd Annual International Conference of the IEEE Engineering in Medicine and Biology Society (EMBS). Boston, Massachusetts USA. 2011; pp. 5993-6. [http://dx.doi.org/10.1109/IEMBS.2011.6091481]

[336] Kreutz M, Anschutz M, Grunendick T, Rick A, Gehlen S, Hoffmann K. Automated Diagnosis of Skin Cancer Using Digital Image Processing and Mixture-of-Experts. In: Heidelberg SB, Ed. Bildverarbeitung fur die Medizin. 2001; Vol. 46: pp. 357-61. [http://dx.doi.org/10.1007/978-3-642-56714-8_66]

[337] Ganster H, Pinz A, Röhrer R, Wildling E, Binder M, Kittler H. Automated melanoma recognition. IEEE Trans Med Imaging 2001; 20(3): 233-9. [http://dx.doi.org/10.1109/42.918473] [PMID: 11341712]

[338] Celebi ME, Schaefer G, Iyatomi H, Stoecker WV, Malters JM, Grichnik JM. An improved objective evaluation measure for border detection in dermoscopy images. Skin Res Technol 2009; 15(4): 444-50. [http://dx.doi.org/10.1111/j.1600-0846.2009.00387.x] [PMID: 19832956]

[339] Schmid-Saugeon P. Lesion detection in dermatoscopic images using anisotropic diffusion and morphological flooding International Conference on Image Processing (ICIP). 449-53.

[340] Celebi ME, Quan W, Hitoshi I, Kouhei S, Huiyu Z, Gerald S. A State-of-the-Art Survey on Lesion Border Detection in Dermoscopy Images In: Dermoscopy Image Analysis, M. E. Celebi, T. Mendonca, and J. S. Marques, Eds., ed: CRC Press, 2015, pp. 97-129. [http://dx.doi.org/10.1201/b19107-5]

[341] Chan T F, Sandberg B Y, Vese L A. Active Contours without Edges for Vector-Valued Images J Vis Commun Image Represent, vol. 11, pp. 130-141, 2000/06/01 2000.

[342] Garnavi R, Aldeen M, Celebi ME. Weighted performance index for objective evaluation of border detection methods in dermoscopy images. Skin Res Technol 2011; 17(1): 35-44.

[http://dx.doi.org/10.1111/j.1600-0846.2010.00460.x] [PMID: 20923454]

[343] Garnavi R, Aldeen M. Optimized weighted performance index for objective evaluation of border-detection methods in dermoscopy images. IEEE Trans Inf Technol Biomed 2011; 15(6): 908-17. [http://dx.doi.org/10.1109/TITB.2011.2170083] [PMID: 22113339]

[344] Ramezani M, Karimian A, Moallem P. Automatic detection of malignant melanoma using macroscopic images. J Med Signals Sens 2014; 4(4): 281-90. [PMID: 25426432]

[345] Marques JS, Barata C, Mendonça T. On the Role of Texture and Color in the Classification of Dermoscopy Images 34th Annual International Conference of the IEEE Engineering in Medicine and Biology Society (EMBS). San Diego, California USA. 2012; pp. 4402-5. 
[http://dx.doi.org/10.1109/EMBC.2012.6346942]

[346] Stanley RJ, Stoecker WV, Moss RH, et al. A basis function feature-based approach for skin lesion discrimination in dermatology dermoscopy images. Skin Res Technol 2008; 14(4): 425-35.

[http://dx.doi.org/10.1111/j.1600-0846.2008.00307.x] [PMID: 18937777]

[347] Stoecker WV, Wronkiewiecz M, Chowdhury R, et al. Detection of granularity in dermoscopy images of malignant melanoma using color and texture features. Comput Med Imaging Graph 2011; 35(2): 144-7.

[http://dx.doi.org/10.1016/j.compmedimag.2010.09.005] [PMID: 21036538]

[348] Haralick RM. Statistical and structural approaches to Texture. Proc IEEE 1979; 67: 786-804. [http://dx.doi.org/10.1109/PROC.1979.11328]

[349] Mitra S, Shankar BU. Medical image analysis for cancer management in natural computing framework. Inf Sci (Ny) 2015; 306: 111-31. [http://dx.doi.org/10.1016/j.ins.2015.02.015]

[350] Lillesand TM, Keifer RW, Chipman JW. Remote Sensing and Image Interpretation In: No. Ed. 5 ed. New York: John Wiley \& Sons Ltd, 2004.

[351] Ruiz D, Berenguer V, Soriano A, Sánchez B. A decision support system for the diagnosis of melanoma: A comparative approach. Expert Syst Appl 2011; 38: 15217-23.

[http://dx.doi.org/10.1016/j.eswa.2011.05.079]

[352] Salah B, Alshraideh M, Beidas R, Hayajneh F. Skin cancer recognition by using a neuro-fuzzy system. Cancer Inform 2011; 10: 1-11. [http://dx.doi.org/10.4137/CIN.S5950] [PMID: 21340020]

[353] Jaleel JA, Salim S, Aswin RB. Computer Aided Detection of Skin Cancer International Conference on Circuits, Power and Computing Technologies (ICCPCT). 1137-42.

[http://dx.doi.org/10.1109/ICCPCT.2013.6528879]

[354] Chiem A, Al-Jumaily A, Khushaba RN. A Novel Hybrid System for Skin Lesion Detection International Conference on Intelligent Sensors, Sensor Networks and Information Processing (ISSNIP). [http://dx.doi.org/10.1109/ISSNIP.2007.4496905]

[355] Patwardhan SV, Dhawan AP, Relue PA. Classification of melanoma using tree structured wavelet transforms. Comput Methods Programs Biomed 2003; 72(3): 223-39.

[http://dx.doi.org/10.1016/S0169-2607(02)00147-5] [PMID: 14554136]

[356] Legesse FB, Medyukhina A, Heuke S, Popp J. Texture analysis and classification in coherent anti-Stokes Raman scattering (CARS) microscopy images for automated detection of skin cancer. Comput Med Imaging Graph 2015; 43: 36-43. [http://dx.doi.org/10.1016/j.compmedimag.2015.02.010] [PMID: 25797604]

[357] Maglogiannis I, Delibasis KK. Enhancing classification accuracy utilizing globules and dots features in digital dermoscopy. Comput Methods Programs Biomed 2015; 118(2): 124-33. [http://dx.doi.org/10.1016/j.cmpb.2014.12.001] [PMID: 25540998]

[358] Rubegni P, Burroni M, Cevenini G, et al. Digital dermoscopy analysis and artificial neural network for the differentiation of clinically atypical pigmented skin lesions: a retrospective study. J Invest Dermatol 2002; 119(2): 471-4. [http://dx.doi.org/10.1046/j.1523-1747.2002.01835.x] [PMID: 12190872]

[359] Sheha M A, Mabrouk M S, Sharawy A. Automatic detection of melanoma skin cancer using texture analysis 2012. J Comput Appl, vol. 42, pp. 22-26, March 2012.

[360] Maglogiannis I, Doukas CN. Overview of Advanced Computer Vision Systems for Skin Lesions Characterization In: IEEE Trans Inf Technol Biomed. 2009; vol. 13.

[361] Garnavi R, Aldeen M, Bailey J. Classification of Melanoma Lesions Using Wavelet-Based Texture Analysis International Conference on Digital Image Computing: Techniques and Applications (DICTA). Sydney, NSW. 2010; pp. 75-81.

[http://dx.doi.org/10.1109/DICTA.2010.22]

[362] Ballerini L, Fisher RB, Aldridge B, Rees J. Non-Melanoma Skin Lesion Classification Using Colour Image Data in a Hierarchical K-NN Classifier 9th IEEE International Symposium on Biomedical Imaging (ISBI). 358-61. [http://dx.doi.org/10.1109/ISBI.2012.6235558]

[363] Doukas C, Stagkopoulos P, Keranoudis CT, Maglogiannis I. Automated Skin Lesion Assessment Using Mobile Technologies and Cloud Platforms 34th Annual International Conference of the IEEE Engineering in Medicine and Biology Society (EMBS). San Diego, California, USA. 2012. [http://dx.doi.org/10.1109/EMBC.2012.6346458]

[364] Noroozi N, Zakerolhosseini A. Computerized measurement of melanocytic tumor depth in skin histopathological images. Micron 2015; 77 : 44-56. [http://dx.doi.org/10.1016/j.micron.2015.05.007] [PMID: 26102548]

[365] White RG, Perednia DA, Schowengerdt RA. Automated feature detection in digital images of skin. Comput Methods Programs Biomed 1991; 34(1): 41-60.

[http://dx.doi.org/10.1016/0169-2607(91)90081-4] [PMID: 2036789] 
[366] Andreassi L, Perotti R, Rubegni P, et al. Digital dermoscopy analysis for the differentiation of atypical nevi and early melanoma: A new quantitative semiology. Arch Dermatol 1999; 135(12): 1459-65. [http://dx.doi.org/10.1001/archderm.135.12.1459] [PMID: 10606050]

[367] Maglogiannis I, Pavlopoulos S, Koutsouris D. An Integrated Computer Supported Acquisition, Handling, and Characterization System for Pigmented Skin Lesions in Dermatological Images In: IEEE Trans Inf Technol Biomed. 2005; 9: pp. 86-98.

[368] Salerni G, Carrera C, Lovatto L, et al. Characterization of 1152 lesions excised over 10 years using total-body photography and digital dermatoscopy in the surveillance of patients at high risk for melanoma. J Am Acad Dermatol 2012; 67(5): 836-45. [http://dx.doi.org/10.1016/j.jaad.2012.01.028] [PMID: 22521205]

[369] Jaworek-Korjakowska J, Kłeczek P. Automatic classification of specific melanocytic lesions using artificial intelligence. BioMed Res Int 2016; 2016: 8934242 .

[http://dx.doi.org/10.1155/2016/8934242] [PMID: 26885520]

[370] Ferris LK, Harkes JA, Gilbert B, et al. Computer-aided classification of melanocytic lesions using dermoscopic images. J Am Acad Dermatol 2015; 73(5): 769-76. [http://dx.doi.org/10.1016/j.jaad.2015.07.028] [PMID: 26386631]

[371] Leo GD, Liguori C, Paolillo A, Sommella P. An improved procedure for the automatic detection of dermoscopic structures in digital ELM images of skin lesions IEEE International Conference on Virtual Environments, Human-Computer Interfaces, and Measurement Systems.

[372] Celebi ME, Iyatomi H, Stoecker WV, et al. Automatic detection of blue-white veil and related structures in dermoscopy images. Comput Med Imaging Graph 2008; 32(8): 670-7. [http://dx.doi.org/10.1016/j.compmedimag.2008.08.003] [PMID: 18804955]

[373] García Arroyo JL, García Zapirain B. Detection of pigment network in dermoscopy images using supervised machine learning and structural analysis. Comput Biol Med 2014; 44: 144-57. [http://dx.doi.org/10.1016/j.compbiomed.2013.11.002] [PMID: 24314859]

[374] Carli P, Giorgi Vd, Chiarugi A, Nardini P, Weinstock MA, Crocetti E, et al. Addition of dermoscopy to conventional nakedeye examination in melanoma screening: A randomized study. J Dermatol 2003; 50: 683-9.

[375] Rastgoo M, Garcia R, Morel O, Marzani F. Automatic differentiation of melanoma from dysplastic nevi. Comput Med Imaging Graph 2015; 43: 44-52.

[http://dx.doi.org/10.1016/j.compmedimag.2015.02.011] [PMID: 25797605]

[376] Barata C, Ruela M, Mendonça T, Marques JS. A bag-of-features approach for the classification of melanomas in dermoscopy images: The role of color and texture descriptors In: Computer vision techniques for the diagnosis of skin cancer, series in BioEngineering, J. Scharcanski and M. E. Celebi, Eds., ed: Springer-Verlag Berlin Heidelberg, 2014, pp. 49 - 69.

[377] Abedini M, Codella N C F, Connell J H, Garnavi R, Merler M, Pankanti S, et al. A generalized framework for medical image classification and recognition IBM J Res Dev 2015; vol. 59 [http://dx.doi.org/10.1147/JRD.2015.2390017]

[378] Li K, Wang F, Zhang L. A new algorithm for image recognition and classification based onimproved Bag of Features algorithm. Optik (Stuttg) 2016; 127: 4736-40.

[http://dx.doi.org/10.1016/j.ijleo.2015.08.219]

[379] Ruela M, Barata C, Marques JS, Rozeira J. A system for the detection of melanomas in dermoscopy images using shape and symmetry features. Comput Methods Biomech Biomed Engin 2015.

[380] Abbas Q, Celebi ME, Serrano C, Garcı'a IFn, Ma G. Pattern classification of dermoscopy images: A perceptually uniform model. Pattern Recognit 2013; 46: 86-97. [http://dx.doi.org/10.1016/j.patcog.2012.07.027]

[381] Dreiseitl S, Ohno-Machado L, Kittler H, Vinterbo S, Billhardt H, Binder M. A comparison of machine learning methods for the diagnosis of pigmented skin lesions. J Biomed Inform 2001; 34(1): 28-36. [http://dx.doi.org/10.1006/jbin.2001.1004] [PMID: 11376540]

[382] Celebi ME, Kingravi HA, Uddin B, et al. A methodological approach to the classification of dermoscopy images. Comput Med Imaging Graph 2007; 31(6): 362-73.

[http://dx.doi.org/10.1016/j.compmedimag.2007.01.003] [PMID: 17387001]

[383] Wazaefi Y, Paris S, Fertil B. Contribution of a classifier of skin lesions to the dermatologist's decision 3rd International Conference on Image Processing Theory, Tools and Applications (IPTA). [http://dx.doi.org/10.1109/IPTA.2012.6469560]

[384] Tabatabaie K, Esteki A. Independent Component Analysis as an Effective Tool for Automated Diagnosis of Melanoma IEEE Cairo International Biomedical Engineering Conference (CIBEC). [http://dx.doi.org/10.1109/CIBEC.2008.4786081]

[385] Jukić A, Kopriva I, Cichocki A. Noninvasive diagnosis of melanoma with tensor decomposition-based feature extraction from clinical color image. Biomed Signal Process Control 2013; 8: 755-63.

[http://dx.doi.org/10.1016/j.bspc.2013.07.001] 
[386] D’Alessandro B, Dhawan AP, Mullani N. Computer Aided Analysis of Epi-illumination and Transillumination Images of Skin Lesions for Diagnosis of Skin Cancers 33rd Annual International Conference of the IEEE EMBS. Boston, Massachusetts USA. 2011. [http://dx.doi.org/10.1109/IEMBS.2011.6090929]

[387] Stoecker WV, Li WW, Moss RH. Automatic detection of asymmetry in skin tumors. Comput Med Imaging Graph 1992; $16(3)$ : $191-7$. [http://dx.doi.org/10.1016/0895-6111(92)90073-I] [PMID: 1623494]

[388] Ng VTY, Fung BYM, Lee TK. Determining the asymmetry of skin lesion with fuzzy borders. Comput Biol Med 2005; 35(2): 103-20. [http://dx.doi.org/10.1016/j.compbiomed.2003.11.004] [PMID: 15567181]

[389] Cascinelli N, Ferrario M, Bufalino R, et al. Results obtained by using a computerized image analysis system designed as an aid to diagnosis of cutaneous melanoma. Melanoma Res 1992; 2(3): 163-70. [http://dx.doi.org/10.1097/00008390-199209000-00004] [PMID: 1450670]

[390] Cavalcanti PG, Scharcanski J, Baranoski GVG. A two-stage approach for discriminating melanocytic skin lesions using standard cameras. Expert Syst Appl 2013; 4054-64. [http://dx.doi.org/10.1016/j.eswa.2013.01.002]

[391] Shimizu K, Iyatomi H, Norton K-A, Celebi ME. Extension of automated melanoma screening for non-melanocytic skin lesions 19th International Conference on Mechatronics and Machine Vision in Practice (M2VIP). 16-9.

[392] Iyatomi H, Oka H, Celebi M E, Ogawa K, Argenziano G, Soyer H P, et al. Computer-Based Classification of Dermoscopy Images of Melanocytic Lesions on Acral Volar Skin J Invest Dermatol 2008; 1-6. [http://dx.doi.org/10.1038/jid.2008.28]

[393] Tasoulis SK, Doukas CN, Maglogiannis I, Plagianakos VP. Classification of Dermatological Images Using Advanced Clustering Techniques 32nd Annual International Conference of the IEEE EMBS. Buenos Aires, Argentina. 2010. [http://dx.doi.org/10.1109/IEMBS.2010.5626242]

[394] Lee TK, McLean DI, Atkins MS. Irregularity index: A new border irregularity measure for cutaneous melanocytic lesions. Med Image Anal 2003; 7(1): 47-64 [http://dx.doi.org/10.1016/S1361-8415(02)00090-7] [PMID: 12467721]

[395] Stanley RJ, Moss RH, Van Stoecker W, Aggarwal C. A fuzzy-based histogram analysis technique for skin lesion discrimination in dermatology clinical images. Comput Med Imaging Graph 2003; 27(5): 387-96. [http://dx.doi.org/10.1016/S0895-6111(03)00030-2] [PMID: 12821032]

[396] Sanchez I, Agaian S. Computer Aided Diagnosis of Lesions Extracted From Large Skin Surfaces IEEE International Conference on Systems, Man, and Cybernetics. [http://dx.doi.org/10.1109/ICSMC.2012.6378186]

[397] Stanley RJ, Stoecker WV, Moss RH. A relative color approach to color discrimination for malignant melanoma detection in dermoscopy images. Skin Res Technol 2007; 13(1): 62-72. [http://dx.doi.org/10.1111/j.1600-0846.2007.00192.x] [PMID: 17250534]

[398] Choi JW, Park YW, Byun SY, Youn SW. Differentiation of benign pigmented skin lesions with the aid of computer image analysis: A Novel Approach. In: Ann Dermatol. 2013; Vol. 25.

[399] Sadeghi M, Razmara M, Lee TK, Atkins MS. A novel method for detection of pigment network in dermoscopic images using graphs. Comput Med Imaging Graph 2011; 35(2): 137-43.

[http://dx.doi.org/10.1016/j.compmedimag.2010.07.002] [PMID: 20724109]

[400] Braun RP, Rabinovitz HS, Oliviero M, Kopf AW, Saurat J-H. Dermoscopy of pigmented skin lesions. J Am Acad Dermatol 2005; 52(1): 109-21. [http://dx.doi.org/10.1016/j.jaad.2001.11.001] [PMID: 15627088]

[401] Anantha M, Moss RH, Stoecker WV. Detection of pigment network in dermatoscopy images using texture analysis. Comput Med Imaging Graph 2004; 28(5): 225-34. [http://dx.doi.org/10.1016/j.compmedimag.2004.04.002] [PMID: 15249068]

[402] Šitum M, Buljan M, Kolić M, Vučić M. Melanoma--clinical, dermatoscopical, and histopathological morphological characteristics. Acta Dermatovenerol Croat 2014; 22(1): 1-12. [PMID: 24813835]

[403] Garbe C, Peris K, Hauschild A, et al. Diagnosis and treatment of melanoma. European consensus-based interdisciplinary guideline - Update 2016. Eur J Cancer 2016; 63: 201-17. [http://dx.doi.org/10.1016/j.ejca.2016.05.005] [PMID: 27367293]

[404] Nowak LA, Ogorzałek MJ, Pawłowski MP. Pigmented Network Structure Detection Using Semi-Smart Adaptive Filters IEEE 6th International Conference on Systems Biology. [http://dx.doi.org/10.1109/ISB.2012.6314155]

[405] Carli P, de Giorgi V, Palli D, Giannotti V, Giannotti B. Preoperative assessment of melanoma thickness by ABCD score of dermatoscopy. J Am Acad Dermatol 2000; 43(3): 459-66. [http://dx.doi.org/10.1067/mjd.2000.106518] [PMID: 10954657] 
[406] Stolz W, Schiffner R, Pillet L, et al. Improvement of monitoring of melanocytic skin lesions with the use of a computerized acquisition and surveillance unit with a skin surface microscopic television camera. J Am Acad Dermatol 1996; 35(2 Pt 1): $202-7$. [http://dx.doi.org/10.1016/S0190-9622(96)90324-2] [PMID: 8708021]

[407] Ferrara G, Argenziano G, Zgavec B, et al. "Compound blue nevus": A reappraisal of "superficial blue nevus with prominent intraepidermal dendritic melanocytes" with emphasis on dermoscopic and histopathologic features. J Am Acad Dermatol 2002; 46(1): 85-9. [http://dx.doi.org/10.1067/mjd.2002.117858] [PMID: 11756951]

[408] Mendonça T, Ferreira PM, Marques JS, Marcal ARS, Rozeira J. PH² - A dermoscopic image database for research and benchmarking. In: IEEE Engineering in Medicine and Biology Society. 2013.

[409] Khan A, Gupta K, Stanley RJ, et al. Fuzzy logic techniques for blotch feature evaluation in dermoscopy images. Comput Med Imaging Graph 2009; 33(1): 50-7.

[http://dx.doi.org/10.1016/j.compmedimag.2008.10.001] [PMID: 19027266]

[410] Higgins HW II, Lee KC, Galan A, Leffell DJ. Melanoma in situ: Part I. Epidemiology, screening, and clinical features. J Am Acad Dermatol 2015; 73(2): 181-90. [http://dx.doi.org/10.1016/j.jaad.2015.04.014] [PMID: 26183967]

[411] Krähn G, Gottlöber P, Sander C, Peter RU. Dermatoscopy and high frequency sonography: Two useful non-invasive methods to increase preoperative diagnostic accuracy in pigmented skin lesions. Pigment Cell Res 1998; 11(3): 151-4. [http://dx.doi.org/10.1111/j.1600-0749.1998.tb00725.x] [PMID: 9730322]

[412] Prayer L, Winkelbauer H, Gritzmann N, Winkelbauer F, Helmer M, Pehamberger H. Sonography versus palpation in the detection of regional lymph-node metastases in patients with malignant melanoma. Eur J Cancer 1990; 26(7): 827-30. [http://dx.doi.org/10.1016/0277-5379(90)90163-N] [PMID: 2145905]

(C) 2018 Okuboyejo and Olugbara.

This is an open access article distributed under the terms of the Creative Commons Attribution 4.0 International Public License (CC-BY 4.0), a copy of which is available at: (https://creativecommons.org/licenses/by/4.0/legalcode). This license permits unrestricted use, distribution, and reproduction in any medium, provided the original author and source are credited. 